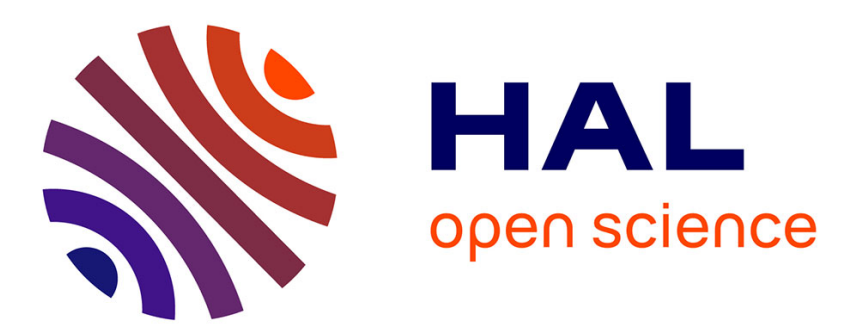

\title{
New excitation functions for proton induced reactions on natural titanium, nickel and copper up to $70 \mathrm{MeV}$
}

Eric Garrido, C. Duchemin, Arnaud Guertin, Ferid Haddad, Nathalie Michel, Vincent Métivier

\section{- To cite this version:}

Eric Garrido, C. Duchemin, Arnaud Guertin, Ferid Haddad, Nathalie Michel, et al.. New excitation functions for proton induced reactions on natural titanium, nickel and copper up to $70 \mathrm{MeV}$. Nuclear Instruments and Methods in Physics Research Section B: Beam Interactions with Materials and Atoms, 2016, 383, pp.191-212. 10.1016/j.nimb.2016.07.011 . hal-02976020

\section{HAL Id: hal-02976020 \\ https://hal.science/hal-02976020}

Submitted on 29 Jan 2021

HAL is a multi-disciplinary open access archive for the deposit and dissemination of scientific research documents, whether they are published or not. The documents may come from teaching and research institutions in France or abroad, or from public or private research centers.
L'archive ouverte pluridisciplinaire HAL, est destinée au dépôt et à la diffusion de documents scientifiques de niveau recherche, publiés ou non, émanant des établissements d'enseignement et de recherche français ou étrangers, des laboratoires publics ou privés. 


\title{
New Excitation Functions for Proton Induced Reactions on Natural Titanium, Nickel and Copper up to $70 \mathrm{MeV}$.
}

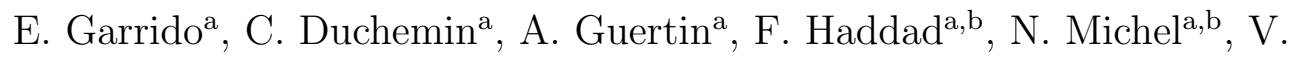 \\ Métivier $^{\mathrm{a}}$ \\ ${ }^{a}$ SUBATECH, Ecole des Mines de Nantes, Université de Nantes, CNRS/IN2P3, Nantes, \\ France \\ ${ }^{b}$ GIP Arronax, 1 rue Aronnax, 44817 Saint-Herblain, France
}

\begin{abstract}
HIGHLIGHTS

- Natural titanium, nickel and copper targets.

- $70 \mathrm{MeV}$ ARRONAX cyclotron proton beam.

- Stacked-foil technique and monitor reactions.

- Experimental cross section values.

- TALYS code version 1.6.
\end{abstract}

ABSTRACT

New excitation functions for proton induced nuclear reactions on natural titanium, nickel and copper were measured, using the stacked-foil technique and gamma spectrometry, up to $70 \mathrm{MeV}$. The experimental cross sections were measured using the Ti-nat(p,x)V-48, Ni-nat(p,x)Ni-57 and Cunat(p,x)Zn-62,Co-56 monitor reactions recommended by the International Atomic Energy Agency (IAEA), depending on the investigated energy range. Data have been extracted for the Ti-nat(p,x)Sc-43,44m,46,47,48, V-48, K42,43, Ni-nat(p,x)Ni-56,57, Co-55,56,57,58, Mn-52,54, Cu-nat(p,x)Cu-61,64, Ni-57, Co-56,57,58,60, Zn-62,65, Mn-54 reactions. Our results are discussed and compared to the existing ones as well as with the TALYS code version 1.6 calculations using default models. Our experimental data are in overall

Email address: Charlotte.Duchemin@subatech.in2p3.fr (C. Duchemin) 
good agreement with the literature. TALYS is able to reproduce, in most cases, the experimental trend. Our new experimental results allow to expand our knowledge on these excitation functions, to confirm the existing trends and to give additional values on a large energy range. This work is in line with the new Coordinated Research Project (CRP) launched by the IAEA to expand the database of monitor reactions.

Keywords: stacked-foil technique, ARRONAX cyclotron, $70 \mathrm{MeV}$ proton beam, titanium, nickel, copper, TALYS 1.6

\section{Introduction}

Our researches are focused on radionuclide production mainly for medical applications, either for therapy or diagnostics. This work is conducted in close collaboration with the GIP ARRONAX that possesses a high energy and high intensity multi-particles cyclotron. In this frame, data were measured for alpha emitters, such as the U-230/Th-226, Th-227/Ra-223 and Ac225/Bi-213 generators, with protons up to $70 \mathrm{MeV}$ (Duchemin et al., 2015a). In this context, several stack of thin foils were irradiated in order to limit the energy uncertainties and ensure the reproducibility of our values. Some monitor foils, made of copper, titanium or nickel, were placed in each stack to quantify the particle beam flux all along the stack. From these irradiated materials, new experimental cross section data have been extracted which allow to expand our knowledge on these excitation functions, to confirm the existing trends and to give additional values on a wider energy range. The data presented in this article are coming from several experiments performed at different dates between February 2014 and December 2015.

In this work, we measured data up to $70 \mathrm{MeV}$ for the Ti-nat(p,x)Sc43,44m,46,47,48, V-48, K-42,43, Ni-nat(p,x)Ni-56,57, Co-55,56,57,58, Mn52,54 and $\mathrm{Cu}-\mathrm{nat}(\mathrm{p}, \mathrm{x}) \mathrm{Cu}-61,64, \mathrm{Ni}-57, \mathrm{Co}-56,57,58,60, \mathrm{Zn}-62,65, \mathrm{Mn}-54$ reactions.

Some of these data are of interest for medical applications and/or monitor reactions. Indeed, Sc-43 and Sc-44 are useful for nuclear imaging (HuclierMarkai et al, 2011, Duchemin et al, 2015b), Sc-47 for therapy (MajkowskaPilip and Bilewicz, 2011). Co-55 and Mn-52 are of interest for diagnostics (Atcher et al., 1980, Jansen et al., 1996, De Reuck et al., 2001, Topping et al., 2013). Several copper radionuclides are suitable for PET imaging (Williams et al., 2005) as $\mathrm{Cu}-61$ and $\mathrm{Cu}-64$. Data on Zn-62 (Okazawa et 
al., 1995) are also of interest since $\mathrm{Cu}-62$ can be produced via its decay. As $\mathrm{Cu}-64$ is a $\beta+$ emitter and a $\beta$ - emitter, it is well suitable for PET imaging (Anderson and Ferdani, 2009) but also for dosimetry and potentially also for therapy (Bryan et al., 2011). In addition, the IAEA have launched a Coordinated Research Project (CRP) in 2012 to get additional data for monitor reactions and medical isotope production (Nichols, A.L. and Capote, R., 2013). A requirement list has been set, including the Ti-nat(p,x)Sc-46, Ni-nat(p,x)Co-56,Co-58,Ni-57, Cu-nat(p,x)Co-58,Zn-62,Zn-65 reactions that have been investigated in this work.

\section{Materials and methods}

\subsection{Experimental set-up and data measurements}

The production cross section data were obtained using the stacked-foils method (Duchemin et al., 2015a, Blessing et al., 1995), which consists in the irradiation of a set of thin foils followed by gamma spectrometry measurements to assess the produced activity of the investigated radionuclide. Our experiments were carried out at the ARRONAX cyclotron (Nantes, France), in the AX hall devoted to experiments in physics, radiolysis and radiobiology (Haddad et al., 2008).

Each thin foil was weighed before irradiation using an accurate scale $\left( \pm 10^{-5} \mathrm{~g}\right)$ and scanned to precisely determine its area. From these values and assuming that the thickness is homogeneous over the whole surface, the thickness was deduced: around $20 \mu \mathrm{m}$ for the titanium and copper foils and $25 \mu \mathrm{m}$ for the nickel foils. All foils were purchased from Goodfellow ${ }^{\circledR}$ with high isotopic and chemical purity: $99.6 \%$ for titanium, $99 \%$ for nickel and $99.9 \%$ for copper. Their isotopic composition is reported in table 1.

\begin{tabular}{c|ccccc}
\multicolumn{6}{c}{ Table 1: isotopic composition of the natural foils from Goodfellow ${ }^{\circledR}$} \\
\hline Ti-nat & Ti-46 & Ti-47 & Ti-48 & Ti-49 & Ti-50 \\
& $8.0 \%$ & $7.5 \%$ & $73.7 \%$ & $5.5 \%$ & $5.3 \%$ \\
\hline \hline Ni-nat & $\mathrm{Ni}-58$ & $\mathrm{Ni}-60$ & $\mathrm{Ni}-61$ & $\mathrm{Ni}-62$ & $\mathrm{Ni}-64$ \\
& $68.27 \%$ & $26.10 \%$ & $1.13 \%$ & $3.59 \%$ & $0.91 \%$ \\
\hline \hline Cu-nat & $\mathrm{Cu}-63$ & $\mathrm{Cu}-65$ & & & \\
& $69.2 \%$ & $30.8 \%$ & & & \\
\hline
\end{tabular}

The incident beam energy was fixed by the setting parameters of the cyclotron with an uncertainty, defined by the cyclotron provider and based 
on simulations, of $\pm 0.5 \mathrm{MeV}$. This energy determination has been validated with previous work and has given data in good agreement with the literature for a wide range of target masses over a wide incident energy range. The beam line is under vacuum and closed using a $75 \mu \mathrm{m}$ thick kapton foil. The stacks were located about $6.8 \mathrm{~cm}$ downstream in air. The energy through each thin foil was determined in the middle of the foil using the SRIM software (Ziegler et al., 2011). Energy losses in the kapton foil and air were taken into account. Aluminum and copper degrader foils, from $100 \mu \mathrm{m}$ to $1 \mathrm{~mm}$ thick, were used to decrease the energy beam all along the stack. Depending on the number of foils, the energy uncertainty increases up to $\pm 2.0 \mathrm{MeV}$ due to spatial and energy straggling and the initial energy beam spread. Typical irradiations were carried out with about 100 nA during 30 minutes (Duchemin et al., 2015a).

The particle flux through the stack was quantified using monitor reactions suggested by the IAEA (Tárkányi, et al., 2001); Ti-nat(p,x)V-48 reaction up to $20 \mathrm{MeV}$, Ni-nat(p,x)Ni-57 reaction between $20 \mathrm{MeV}$ and $46 \mathrm{MeV}, \mathrm{Cu}-\mathrm{nat}(\mathrm{p}, \mathrm{x}) \mathrm{Zn}-62$ reaction between $46 \mathrm{MeV}$ and $60 \mathrm{MeV}$, and the $\mathrm{Cu}-\operatorname{nat}(\mathrm{p}, \mathrm{x}) \mathrm{Co}-56$ reaction above $60 \mathrm{MeV}$.

During the irradiation, an instrumented beam stop is used to control the beam current stability. It can not be used as Faraday cup since it is not equipped with an electron suppression device, which is required for a precise beam current measurement. However, using the number of charges collected with the instrumented beam stop, the cross section values have been found in agreement within $5 \%$ in average with those presented in this article and obtained using monitor reactions.

After some cooling time (around 14 hours after the end of irradiation), activity measurements were performed using a high purity germanium detector, with low-background lead and copper shield, from Canberra ${ }^{\circledR}$. Gamma spectra were recorded using the LV is software from Ortec ${ }^{\circledR}$ in a suitable geometry previously calibrated with standard $\gamma$ sources (Co-57,60 and Eu-152) from Lea Cerca (France).

Samples were placed at a height of $19 \mathrm{~cm}$ from the detector in order to reduce the dead time and the effect of sum peaks. The dead time during measurements was always kept below $10 \%$.

The activity values of the produced radionuclides were derived from the spectra and libraries containing the nuclear decay data given in tables 2, 4 and 6, using the FitzPeaks Gamma Analysis and Calibration Software (JF Computing Services). All foils were counted three times. The first activity 
measurements were performed for one hour, the day after irradiation; the second ones were started one week later, with a counting time between 24 hours and 60 hours. Third measurements were performed to validate the activity values obtained with the two other measurements, to get the activity of some radionuclides after the decay of their parents and to measure long lived radionuclides.

\subsection{Cross section calculation}

Knowing the precise thickness of the foil and the total activity of each radionuclide produced in the target, their production cross section are calculated using the activation formula (1) with the appropriate particle flux.

$$
\sigma(E)=\frac{\text { Act } \cdot \mathrm{A}}{\chi \cdot \Phi \cdot \mathrm{N}_{a} \cdot \mathrm{M} \cdot\left(1-\exp ^{-\lambda \mathrm{t}}\right)}
$$

In equation (1), the production cross section $\sigma(\mathrm{mb})$ of a radionuclide at a given energy, E, depends on its measured activity corrected to the time at the end of irradiation Act $(\mathrm{Bq})$, its decay constant $\lambda\left(\mathrm{s}^{-1}\right)$, its atomic mass A $\left(\right.$ g. $\left.\mathrm{mol}^{-1}\right)$, its areal density $\mathrm{M}\left(\mathrm{g} . \mathrm{cm}^{-2}\right)$, its chemical purity and isotopic abundance $\chi$, the Avogadro constant $\left(\mathrm{N}_{a}\right)$, the irradiation duration $\mathrm{t}(\mathrm{s})$ and the beam current $\Phi\left(\mathrm{p} . \mathrm{s}^{-1}\right)$.

In our experiment, and because we use thin foils, each one receives the same beam current as the monitor foil that follows. It is then possible to define a relative equation (2) in which the knowledge of the beam current is no longer necessary. In this equation, the prime parameters are associated with the radionuclide used as monitor, while the others relate to the radionuclide for which the cross section is investigated.

$$
\sigma(E)=\sigma^{\prime}\left(E^{\prime}\right) \cdot \frac{\chi^{\prime} \cdot \mathrm{Act} \cdot \mathrm{A} \cdot \mathrm{M}^{\prime} \cdot\left(1-\exp ^{-\lambda^{\prime} \mathrm{t}}\right)}{\chi \cdot \mathrm{Act}^{\prime} \cdot \mathrm{A}^{\prime} \cdot \mathrm{M} \cdot\left(1-\exp ^{-\lambda \mathrm{t}}\right)}
$$

The cross section uncertainty is estimated with a propagation error cal-

culation. Since all the parameters of equation (2) are independent, the total error is expressed as a quadratic sum (see equation (3)).

$$
\frac{\Delta \sigma}{\sigma}=\sqrt{\left(\frac{\Delta \sigma^{\prime}}{\sigma^{\prime}}\right)^{2}+\left(\frac{\Delta \text { Act }}{\text { Act }}\right)^{2}+\left(\frac{\Delta \text { Act'}^{\prime}}{\text { Act' }}\right)^{2}+\left(\frac{\Delta \mathrm{M}}{\mathrm{M}}\right)^{2}+\left(\frac{\Delta \mathrm{M}^{\prime}}{\mathrm{M}^{\prime}}\right)^{2}}
$$


Main uncertainties come from the measured activities (less than $10 \%$ in most cases), the areal density of the foils (around $1 \%$ ) and the uncertainty on the recommended cross section values. Since no uncertainty is given for the recommended cross section values, we have decided to use the uncertainty of the nearest experimental value used by the IAEA to perform the adjustment. It leads to an uncertainty of $8 \%$ in average. The contribution of the uncertainty on the irradiation time is not significant and has been neglected.

\subsection{Comparison with the TALYS 1.6 code}

The cross section values, shown in figures 1 to 26 , are compared to the TALYS code version 1.6 released in December, 2013 (Koning and Rochman, 2012). TALYS is a nuclear reaction program to simulate reaction induced by light particles on nuclei heavier than carbon. It incorporates many theoretical models to predict observables including theoretical cross section values as a function of the incident particle energy (from $1 \mathrm{keV}$ to $1 \mathrm{GeV}$ ). A combination of models that better describes the whole set of available data for all combination of projectiles, targets and incident energies have been defined by the authors and put as default in the code. This way, the code can be executed with an input file that contains a minimal set of information: the projectile type and its incident energy, the target type and its mass. The experimental data obtained in this work are compared to TALYS with default models.

\section{Results and discussions}

Our production cross section values, obtained via a relative calculation using the recommended monitor reactions stated in the previous section, are presented in tables 3,5 and 7 . Our results are plotted as full circles in figures 1 to 26 .

\subsection{Proton induced reactions on natural titanium}

In this part, the production cross sections values of vanadium, scandium and potassium radionuclides induced by protons interacting with natural titanium are shown. No data for the Ti-nat $(\mathrm{p}, \mathrm{x}) \mathrm{V}-48$ reaction has been obtained under $20 \mathrm{MeV}$, where it was used as monitor. The physical characteristics of the investigated radionuclides are summarized in table 2 and the associated production cross section numerical values are presented in table 3 . 


\subsubsection{Production of $S c-43$}

Sc-43 has a half-life of $\mathrm{T}_{1 / 2}=3.891(12) \mathrm{h}$. It is a $100 \% \beta+$ emitter and decays to Ca-43 (stable), by emitting a $\gamma$ ray at $372.9 \mathrm{keV}$ (see table 2 ) with a branching ratio of $22.5 \%$, used to deduce its activity. As there is some cooling time of about 14 hours between the end of irradiation and the activity measurements, the short half-life of Sc-43 and its low production cross section have not allowed to detect and quantify Sc-43 in all the irradiated targets. When the Sc-43 activity in the target was high enough to be quantified by our experimental device, the estimated uncertainty on fit of the number of counts may be up to $20 \%$. In addition, Sc-43 has only one detectable gamma line, common to K-43 which is also produced in the target above $30 \mathrm{MeV}$ (see table 2). The activity of K-43 was deduced from this peak using its others detectable gammas, resulting on an additional source of uncertainty for the determination of Sc-43 activity. Our results obtained above $30 \mathrm{MeV}$ (see figure 1) give an order of magnitude of the Sc-43 cross section and further experiments are needed to complete its trend. The TALYS code (version 1.6 with default models) doesn't give satisfactory results for this reaction.

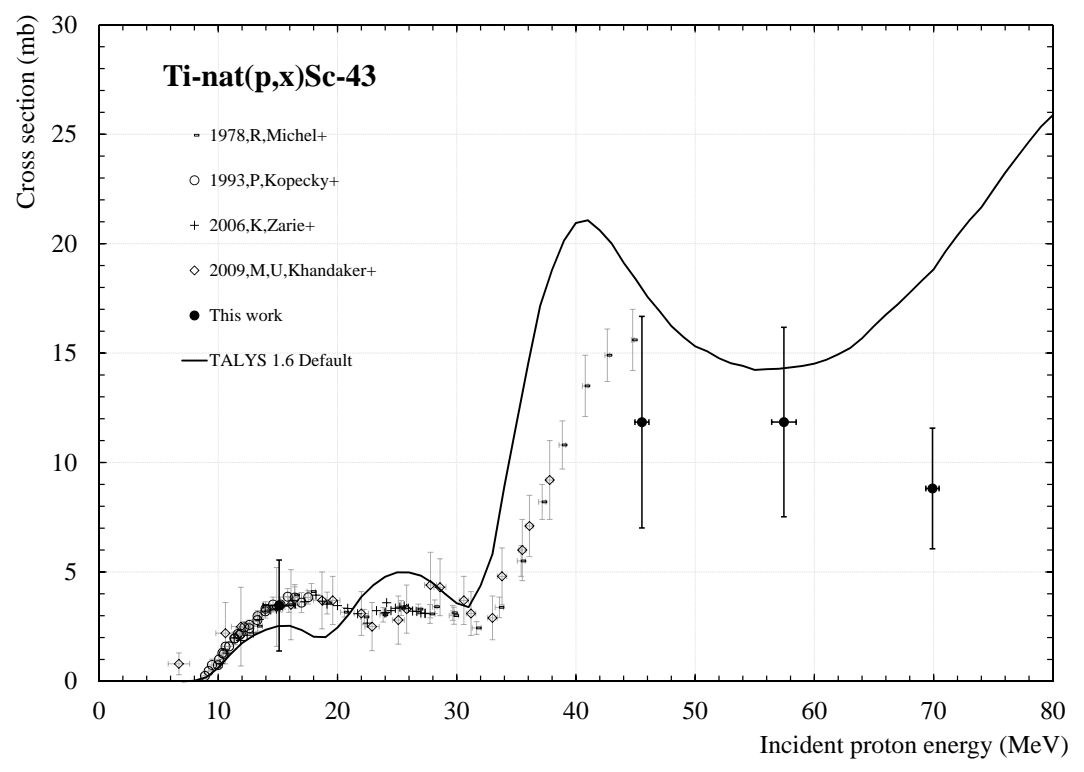

Figure 1: Ti-nat $(\mathrm{p}, \mathrm{x}) \mathrm{Sc}-43$ excitation function. 


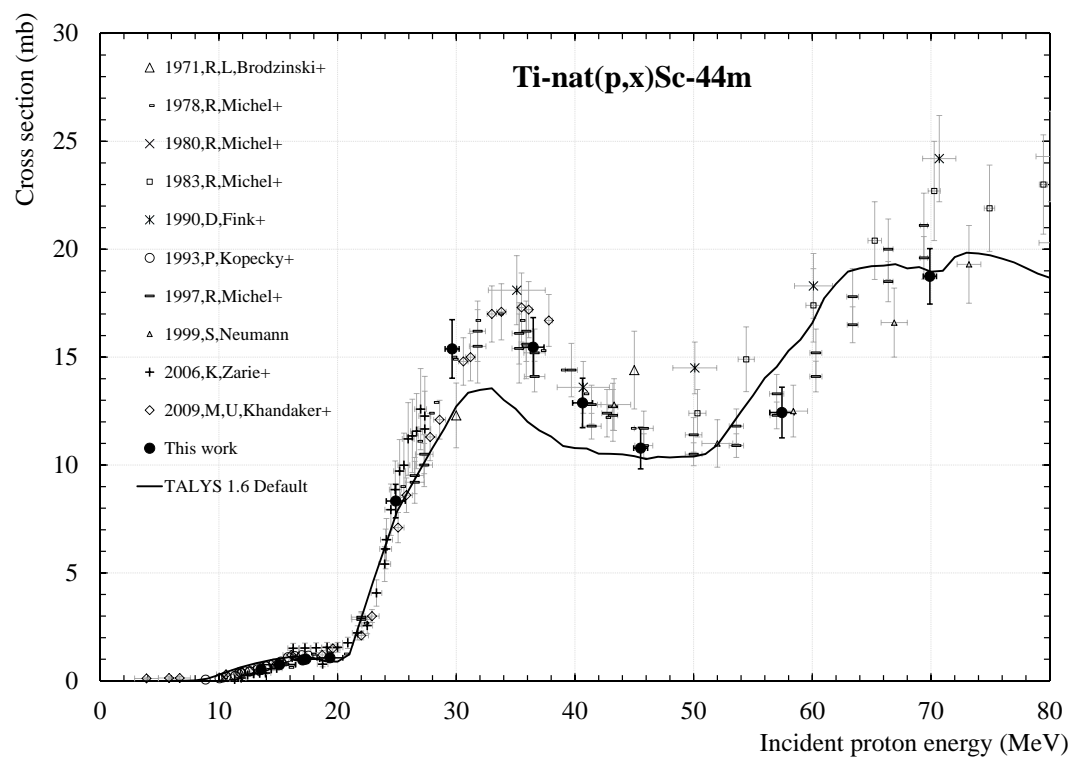

Figure 2: Ti-nat $(\mathrm{p}, \mathrm{x}) \mathrm{Sc}-44 \mathrm{~m}$ excitation function.

\subsubsection{Production of $S c-44 m$}

Sc-44m $\left(\mathrm{T}_{1 / 2}=58.6(1) \mathrm{h}\right)$ is of interest for medical applications as it can be used as in-vivo generator (Huclier-Markai et al., 2011, Duchemin et al., 2015b) producing its ground state Sc-44g, useful for diagnostics. It can also be used in the Sc-44/Sc-47 theranostic pair (Müller et al., 2014). It decays by Electron Capture (EC) process (1.20 (7) \%) to Ca-44 (stable) by emitting three $\gamma$ rays of $1001.83(1.20 \%), 1126.06(1.20 \%)$ and $1157.00 \mathrm{keV}$ (1.20\%). It mainly decays by Internal Transition (IT), at 98.80 (7) \%, to its ground state $\mathrm{Sc}-44 \mathrm{~g}\left(\mathrm{~T}_{1 / 2}=3.97(4) \mathrm{h}\right)$ by emitting an intense $\gamma$ ray at $271.13 \mathrm{keV}$ (table 2). The high branching ratio of this last gamma line was used to extract the Sc-44m production cross section.

The results of the Ti-nat(p,x)Sc-44m excitation function are plotted in figure 2. Below $45 \mathrm{MeV}$, all the experimental values are in agreement, including the results of this work. Above this energy, our data are in agreement with Michel et al., 1997 but further measurements are needed to better describe the curve. TALYS gives a good overall cross section estimate even if the amplitude of the peak at $32 \mathrm{MeV}$ is underestimated. Looking at the amount of experimental results, Sc-44m should be considered for monitor reaction below $45 \mathrm{MeV}$. Sc-44m has a pretty long half-life (higher than 2 days) 
and an easily detectable gamma line for activity measurements.

\subsubsection{Production of $S c-46$}

Sc-46 has a ground state Sc-46g and a metastable state Sc-46m. Sc-46m, with a very short half-life $\left(\mathrm{T}_{1 / 2}=18.75(4) \mathrm{s}\right)$, decays by IT $(100 \%)$ to Sc$46 \mathrm{~g}$ by emitting an intense $\gamma$ ray of $142.528 \mathrm{keV}$. The half-life of Sc- $46 \mathrm{~m}$ is so short, that, at the time of our activity measurements, all the Sc- $46 \mathrm{~m}$ has decayed to Sc-46g ( $\mathrm{T}_{1 / 2}=83.79$ (4) days). We hence measured cumulative Sc- $46 \mathrm{~m}+\mathrm{g}$ activities. Results relative to the $\mathrm{Sc}-46 \mathrm{~m}+\mathrm{g}$ cross section are plotted in figure 3 .

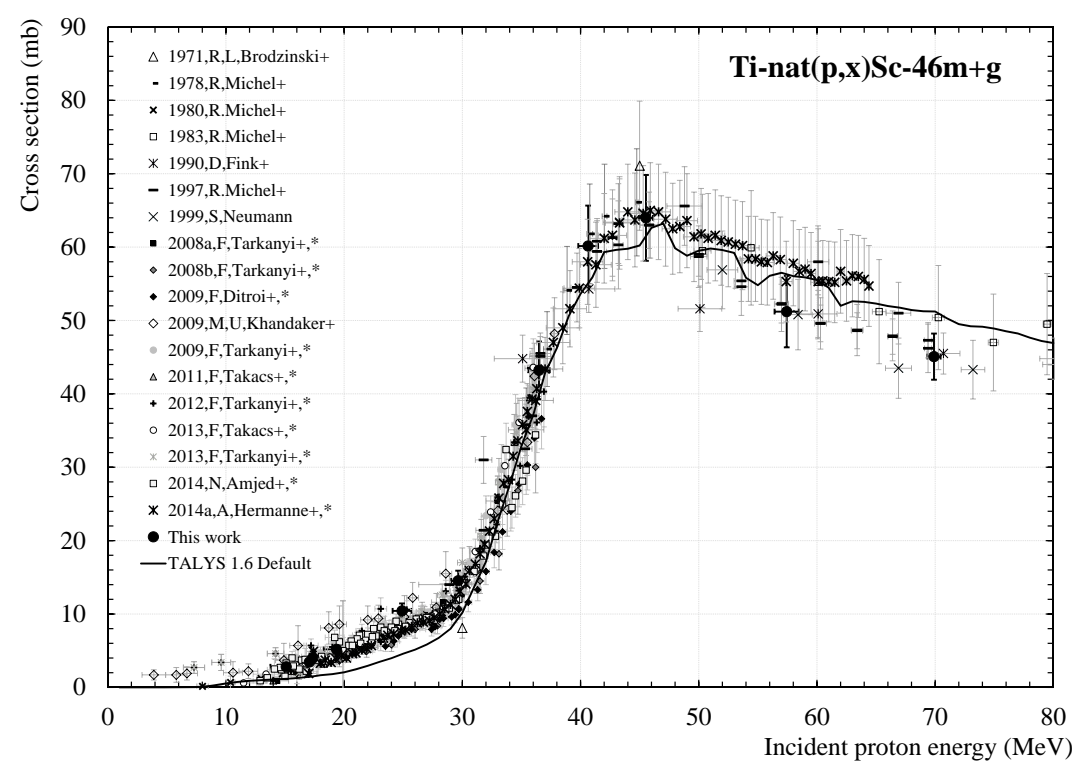

Figure 3: Ti-nat $(\mathrm{p}, \mathrm{x}) \mathrm{Sc}-46 \mathrm{~m}+\mathrm{g}$ excitation function.

The Ti-nat $(\mathrm{p}, \mathrm{x}) \mathrm{Sc}-46 \mathrm{~m}+\mathrm{g}$ reaction is considered by the IAEA as potential new monitor reaction (Tárkányi et al., 2012-2016) as Sc-46g has a long halflife and high cross section. Our data show a good agreement with all the general trend up to $45 \mathrm{MeV}$. From this energy, our data are close to the values of Michel et al., 1997 and Neumann, 1999. The recent values of Hermanne et al., 2014a are $10 \%$ higher than our data but still agree within the error bars. TALYS 1.6 default gives very good results from $30 \mathrm{MeV}$. 


\subsubsection{Production of $S c-47$}

Sc-47 is particularly promising for $\beta$ - targeted therapy (Majkowska-Pilip and Bilewicz, 2011) and can be used for theranostic (Müller et al., 2014) with Sc-44. It has a half-life of $3.3492(6) \mathrm{d}$ and decays by $\beta$ - process at $100 \%$ to Ti-47 (stable) emitting an intense $\gamma$ ray at $159.377 \mathrm{keV}$ (cf. table $2)$. This $\gamma$ line is used to derive the Sc-47 activity from the $\gamma$ spectra. The Ti-nat(p,x)Sc-47 excitation function is plotted in figure 4 .

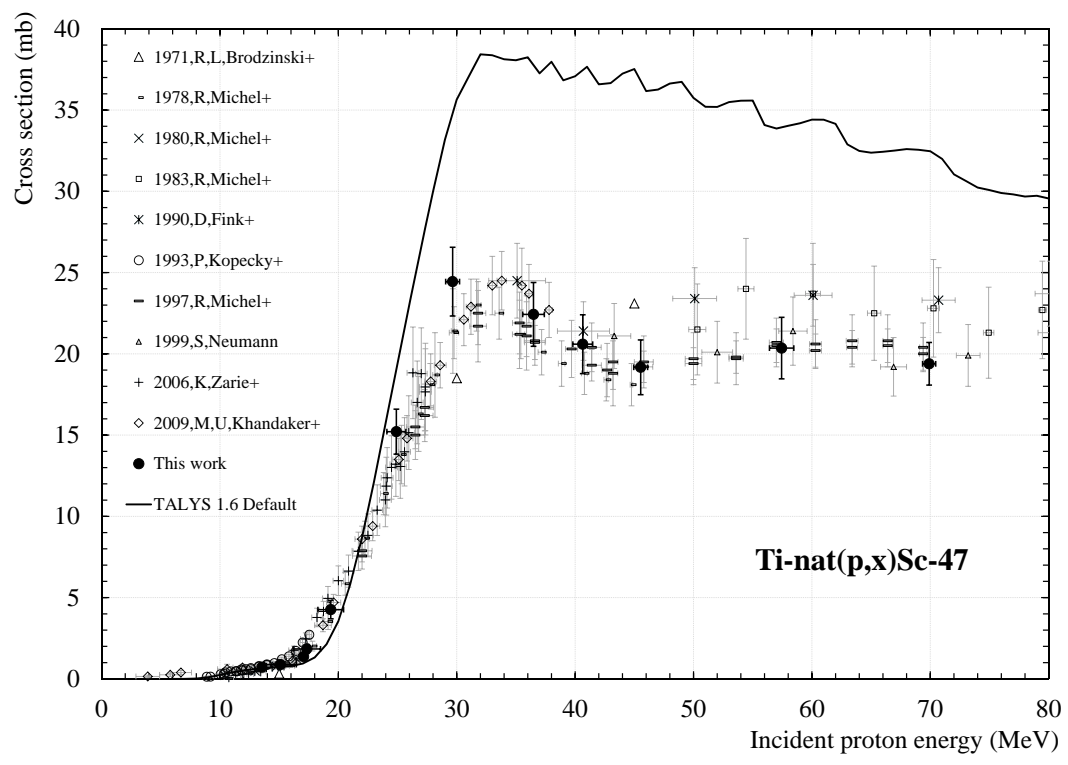

Figure 4: Ti-nat $(\mathrm{p}, \mathrm{x}) \mathrm{Sc}-47$ excitation function.

Our data are in overall good agreement with the available experimental datasets, except with Bordzinsky et al., 1971, Michel et al., 1983 and Fink et al., 1990, that show higher values than the general behaviour. Further values are needed between 25 and $40 \mathrm{MeV}$ to better assess the maximum of the cross section. TALYS (1.6 Default) is not able to reproduce the experimental values for this reaction.

\subsubsection{Production of $S c-48$}

Sc-48, with a half-life of 43.67 (9) h, decays to Ti-48 (stable) by $\beta$ - emission $(100 \%)$. It emits three $\gamma$ lines with high branching ratio (higher than 97 \%) of $983.526,1037.522$ and $1312.120 \mathrm{keV}$, and a $\gamma$ line with a lower intensity of $175.361 \mathrm{keV}$ (7.48 (10) \%). In table 2, only two gamma lines are summa- 


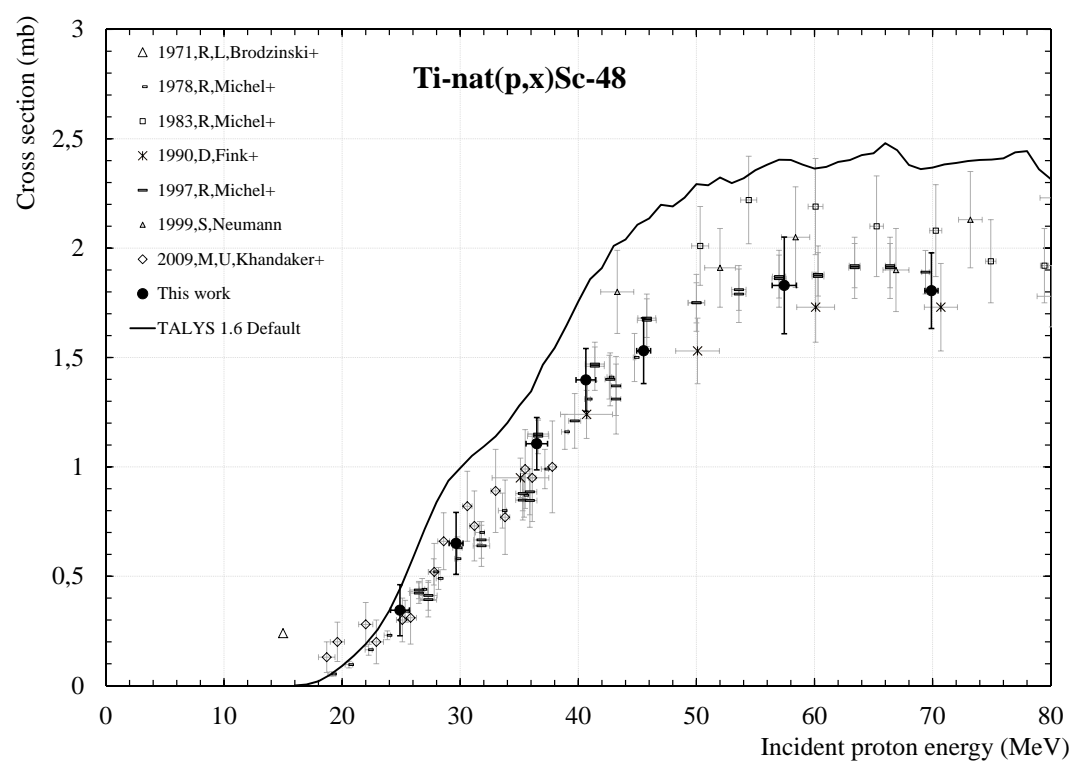

Figure 5: Ti-nat $(\mathrm{p}, \mathrm{x}) \mathrm{Sc}-48$ excitation function.

rized which correspond to those used to determine Sc-48 activity. Only those two $\gamma$ lines have been used as $\mathrm{V}-48\left(\mathrm{~T}_{1 / 2}=15.9735(25) \mathrm{d}\right)$ is also produced in the titanium target and emits two $\gamma$ lines at 983.526 and $1312.120 \mathrm{keV}$ (see table 2) that are common with Sc-48. The Sc-48 production cross section values are presented in figure 5 .

Our data are in agreement with most of the published data. Data published in 1971 and 1983 give higher cross section values than the general behaviour, as already highlighted for the previous investigated scandium isotopes. The TALYS code overestimates the amplitude by $30 \%$ in comparison with our experimental values, but gives the good trend.

\subsubsection{Production of $V-48$}

$\mathrm{V}$-48 is a $100 \% \beta+$ emitter with a half-life of 15.9535 (25) days. It decays by emitting three main $\gamma$ rays (see table 2 ).

In each foil, the $\mathrm{V}-48$ activity value has been determined after the complete decay of Sc-48 $\left(\mathrm{T}_{1 / 2}=43.67 \mathrm{~h}\right.$ ). Our new values (see figure 6 ), obtained above $20 \mathrm{MeV}$, are in agreement with the existing experimental data and with the recommended cross section values from the IAEA (Tárkányi et al., 2001). TALYS is able to reproduce this excitation function, even if the maximum is overestimated by $25 \%$. 


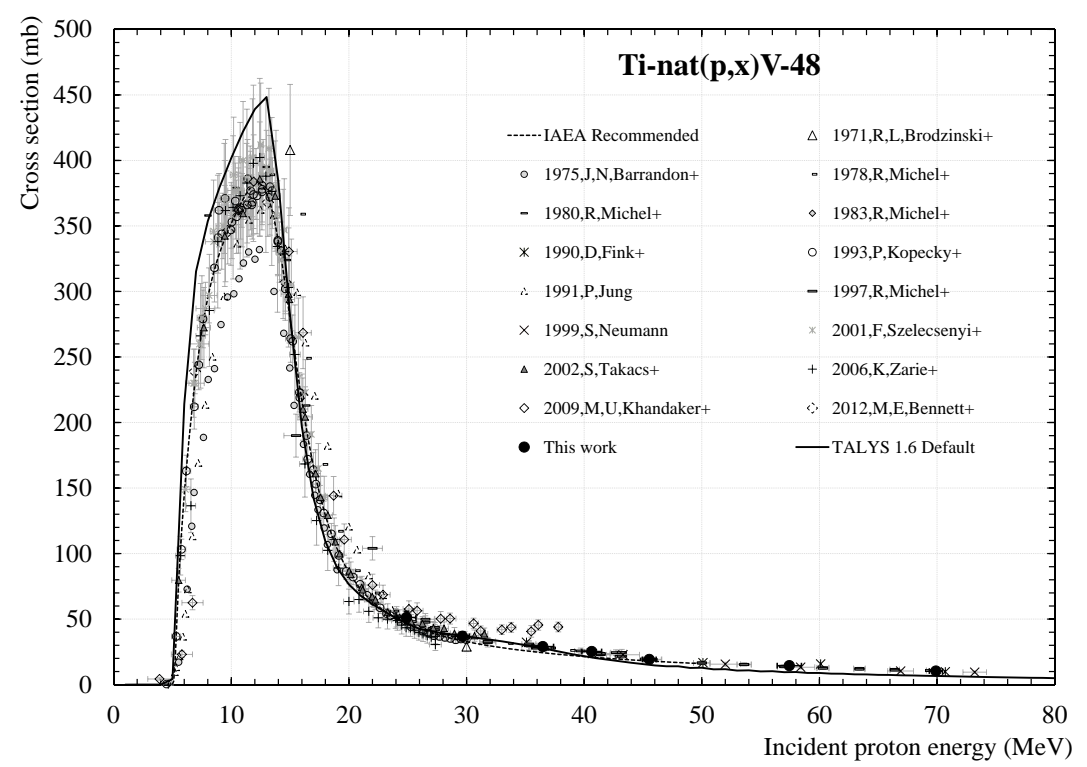

Figure 6: Ti-nat $(\mathrm{p}, \mathrm{x}) \mathrm{V}-48$ excitation function.

\subsubsection{Production of $K-42$}

K-42, with a half-life of 12.260 (3) hours, decays by $\beta$ - process $(100 \%)$ to Ca-42 (stable). It emits a $\gamma$ ray of $1524.7 \mathrm{keV}$ with a branching ratio of 18 $\%$. This isotope can only be produced with protons with an energy higher than $40 \mathrm{MeV}$ through $(\mathrm{p}, 4 \mathrm{p}+\mathrm{xn})$ reactions (see table 2$)$.

Due to the high energy threshold (see table 2), only three cross section values have been obtained in this work, plotted in figure 7 . These data agree with the ones obtained by Michel et al., 1983, Fink et al., 1990 and Neumann, 1999, within their error bars. Further experimental results are needed to have a complete dataset, especially below $60 \mathrm{MeV}$. TALYS doesn't reproduce the experimental trend.

\subsubsection{Production of $K-43$}

K-43 has a half-life of 22.3 (1) hours and decays by $\beta$ - emission at $100 \%$ to Ca-43 (stable), emitting four gamma rays with a branching ratio higher than $11 \%$ (see table 2). Among these $\gamma$ lines, one is common to Sc-43. Its contribution has been deduced to get K-43 activity. The three others $\gamma$ lines have been also used to measure K-43 activity.

Our data obtained on the energy range $40-70 \mathrm{MeV}$ are plotted in figure 


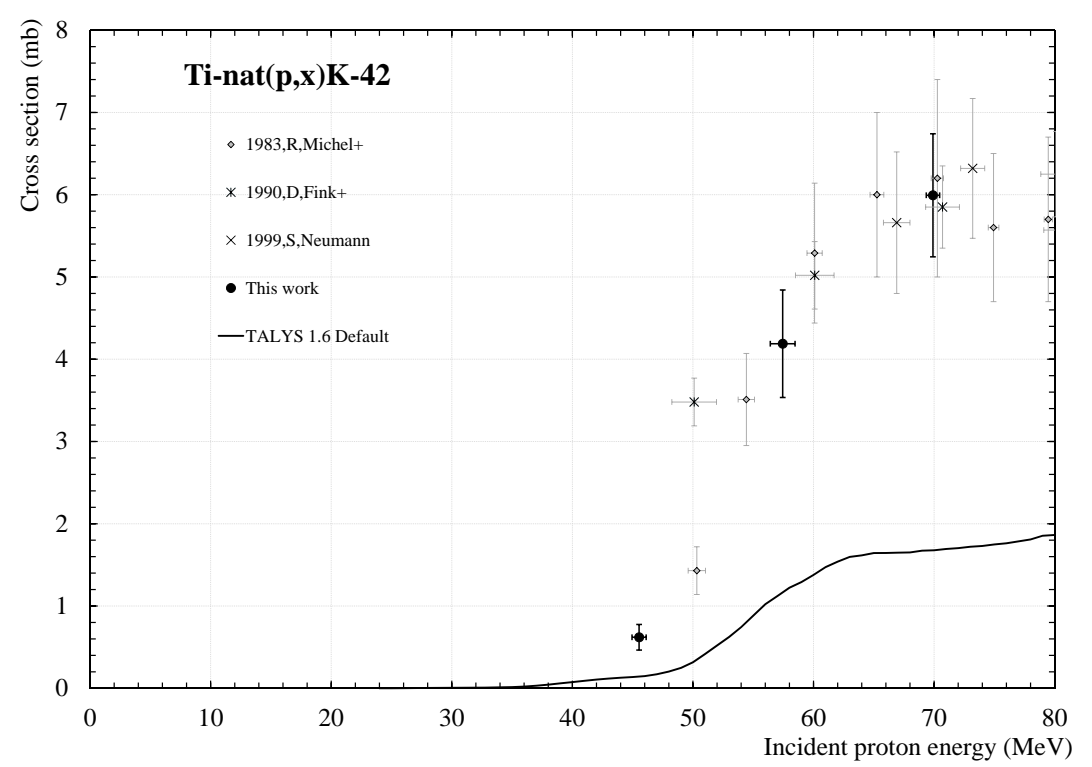

Figure 7: Ti-nat(p,x)K-42 excitation function.

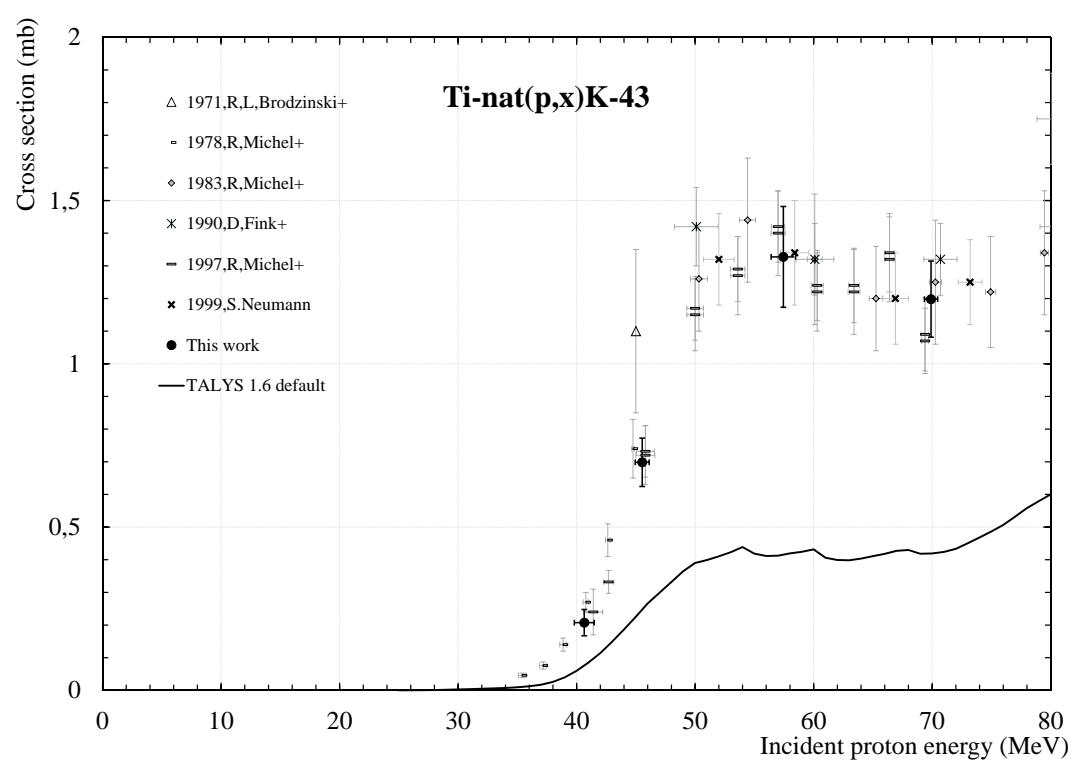

Figure 8: Ti-nat(p,x)K-43 excitation function.

8. They are in good agreement with the literature. Additional results are 
needed between $40 \mathrm{MeV}$ and $50 \mathrm{MeV}$ to refine the $\mathrm{K}-43$ production cross section trend. TALYS is not able to reproduce the experimental cross section values. 


\subsection{Proton induced reactions on natural nickel}

The Ni-nat $(\mathrm{p}, \mathrm{x}) \mathrm{Ni}-57$ reaction is already defined as monitor reaction, with recommended cross section values evaluated by the IAEA. This reaction has been used to quantify the particle beam flux through our foils irradiated with protons between $20 \mathrm{MeV}$ and $46 \mathrm{MeV}$. Our new results related to the production cross sections of nickel, cobalt and manganese isotopes in natural nickel are presented afterwards. Their physical characteristics are listed in table 4 and their associated production cross section values are listed in table 5 .

\subsubsection{Production of Ni-57}

Ni-57 has a half-life of $\mathrm{T}_{1 / 2}=35.6(6) \mathrm{h}$. It decays to Co-57 $\left(\mathrm{T}_{1 / 2}=\right.$ 271.79 (9) days) by $\mathrm{EC} / \beta+$ emission process, emitting four principal $\gamma$ rays, listed in table 4 , used to deduce its activity.

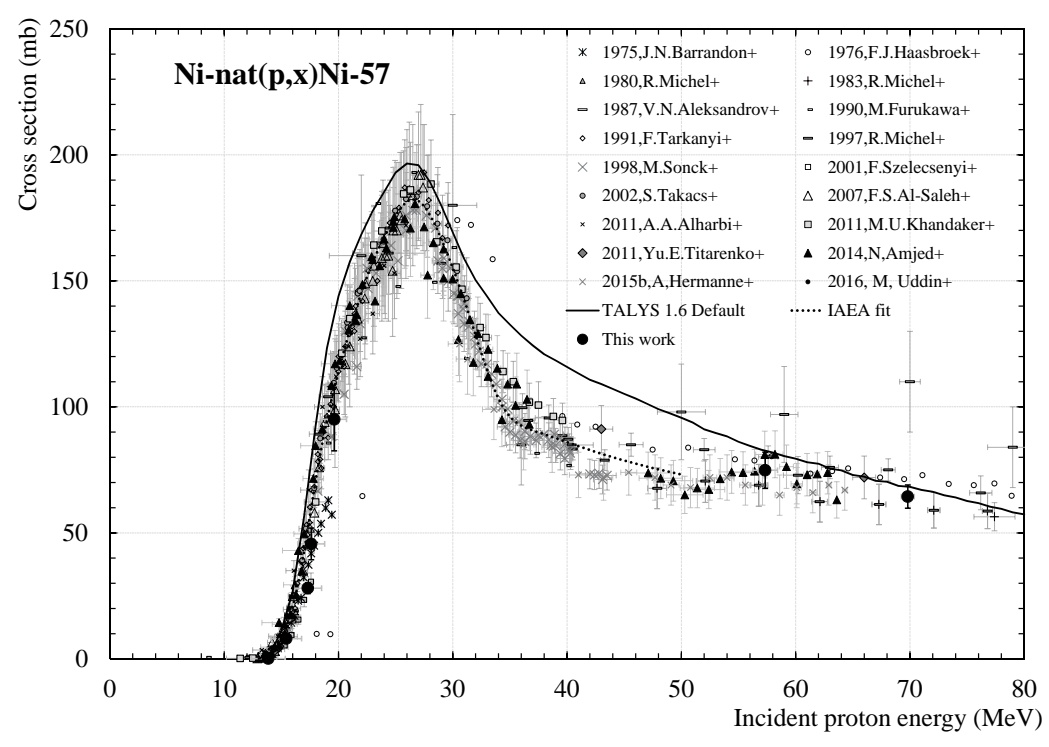

Figure 9: Ni-nat(p,x)Ni-57 excitation function.

The amount of studies for the Ni-nat(p,x)Ni-57 reaction below $50 \mathrm{MeV}$ allowed the International Atomic Energy Agency (IAEA) to set recommended cross section values for this reaction. Our data are plotted in figure 9. They were measured below $20 \mathrm{MeV}$ and above $46 \mathrm{MeV}$. They are in good agreement with the existing experimental values and with the recommended cross 


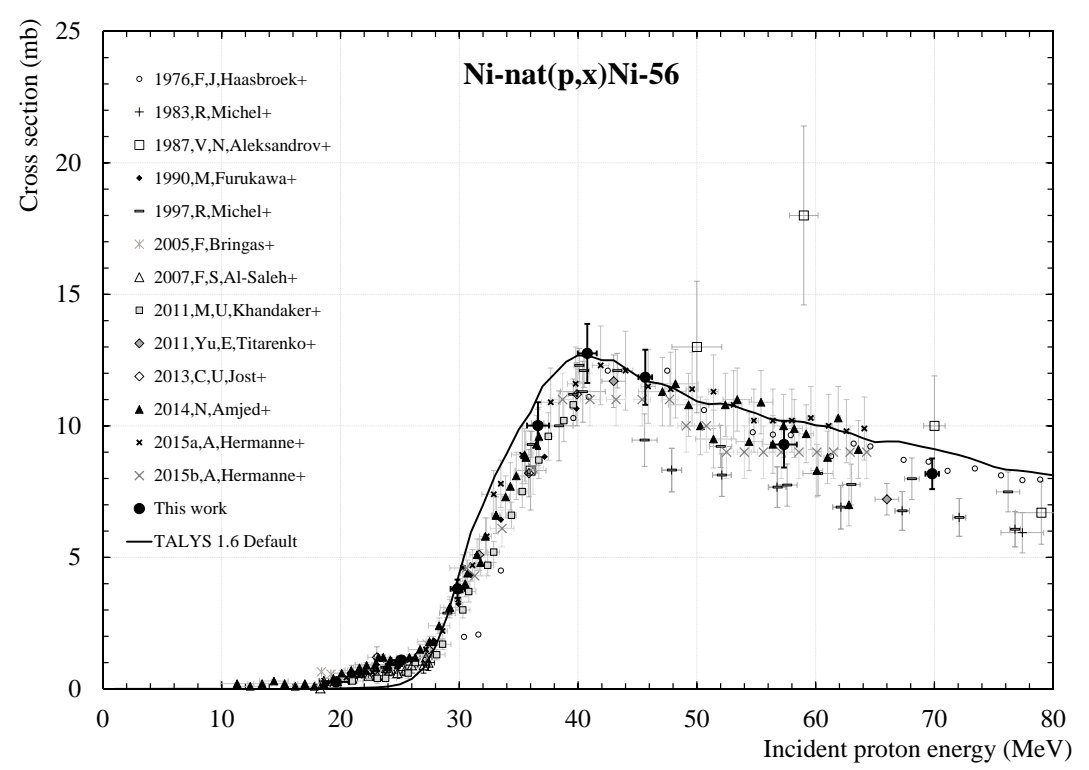

Figure 10: Ni-nat(p,x)Ni-56 excitation function.

section. TALYS 1.6 Default gives a good trend but overestimated in comparison with the experimental results.

\subsubsection{Production of $\mathrm{Ni}-56$}

Ni-56, with a half-life of 6.077 (12) days, decays by EC/ $\beta+$ emission to Co-56 $\left(\mathrm{T}_{1 / 2}=77.27\right.$ (3) days). The gamma lines used to determine Ni-56 activity are summarized in table 4 . The associated cross section values are plotted in figure 10 .

Our data follow the general trend in the whole energy range. Above 40 $\mathrm{MeV}$, the values of Michel et al., 1997, are lower. The TALYS code gives good results above $40 \mathrm{MeV}$.

\subsubsection{Cumulative production of Co-55}

Co-55 is a CE/ $\beta+$ emitter of interest for Position Emission Tomography (Jansen et al., 1996, De Reuck et al., 2001), with a half-life of 17.53 (3) hours. It decays to Fe-55 (2.73 (3) years, no gamma emission). The gamma lines used to extract the Co-55 activity are listed in table 4 . With nickel as target, $\mathrm{Ni}-55\left(\mathrm{~T}_{1 / 2}=209 \mathrm{~ms}\right)$ is produced via the $\mathrm{Ni}-58(\mathrm{p}, \mathrm{p}+3 \mathrm{n})$ reaction above 39.8 $\mathrm{MeV}$ and decays to Co-55. Due to the very short half-life of Ni-55, our Co-55 production cross section results are then cumulative above $39.8 \mathrm{MeV}$. 


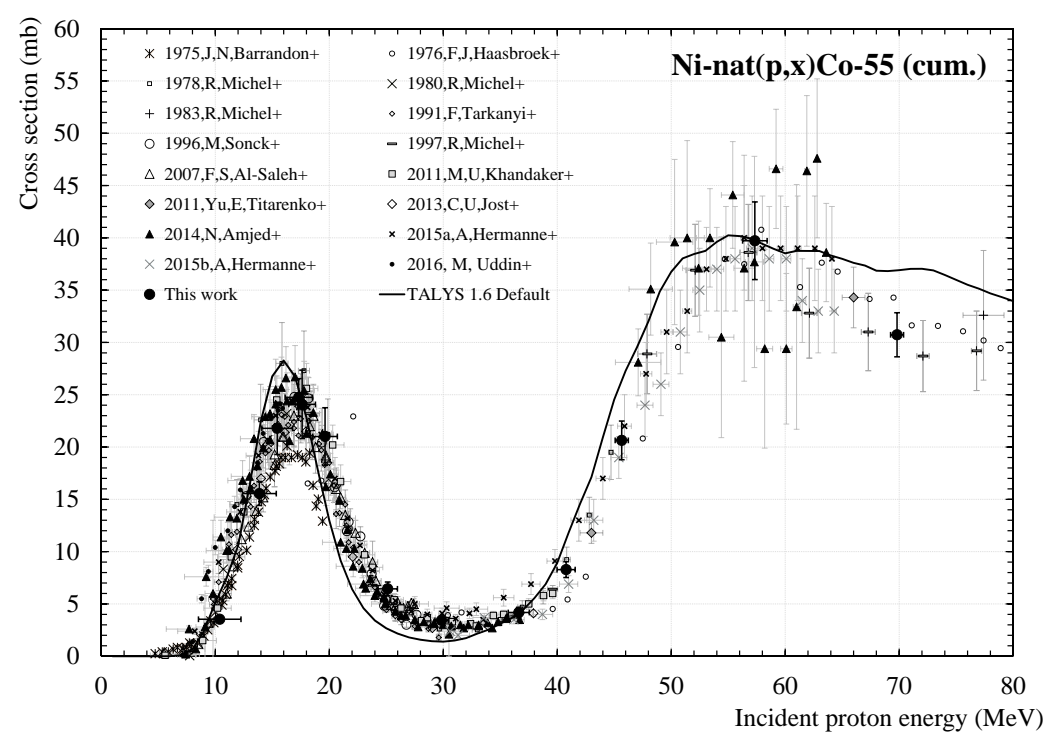

Figure 11: Ni-nat(p,x)Co-55 (cum.) excitation function.

Our data are in overall good agreement with all the existing data on the whole energy range. However, the data of Amjed et al., 2014, are quite scattered. There is an energy shift between the TALYS results and the experimental data between 14 and $30 \mathrm{MeV}$, but it gives satisfactory results in overall.

\subsubsection{Cumulative production of Co-56}

Co-56 has a half-life of 77.27 (3) days and decays by $\mathrm{CE} / \beta+$ process to Fe-56 (stable) by emitting 8 main $\gamma$ rays, used to determine the activity (see table 4). Co-56 activity is obtained after the total decay of $\mathrm{Ni}-56\left(\mathrm{~T}_{1 / 2}=\right.$ 6.077 (12) days), also produce in the nickel target, and which decays to Co-56 as specified in part 3.2.2. The Co-56 cross section values, presented in figure 12 , are cumulative.

Our data are consistent with the exiting values on the whole energy range. However, the experimental values of Khandaker et al., 2011, are higher between 35 and $45 \mathrm{MeV}$ in comparison to our data and those of Michel et al., 1983, are lower. This energy range contains the maximum of the Co-56 cumulative cross section and furthers experiments seems needed to refine it. The values of Aleksandrov et al., 1987, are dispersed above $55 \mathrm{MeV}$, as highlighted with the Ni-56 production cross section. The TALYS code gives very 


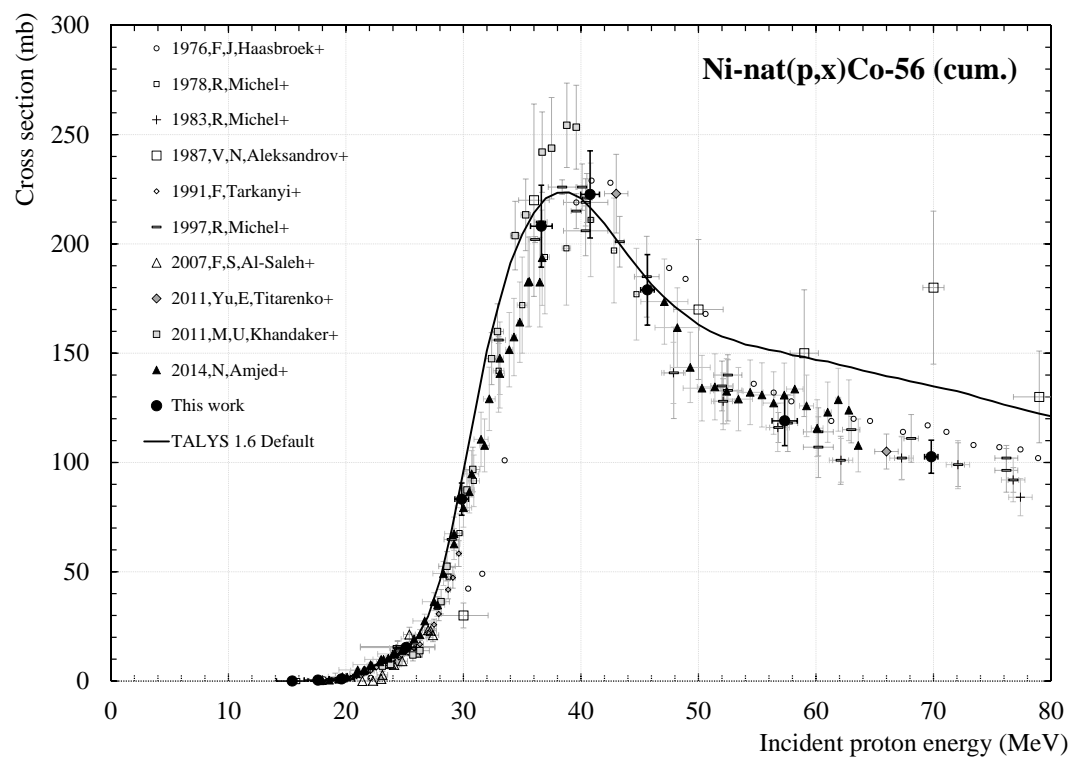

Figure 12: Ni-nat(p,x)Co-56 (cum.) excitation function.

satisfactory results up to $50 \mathrm{MeV}$.

\subsubsection{Cumulative production of $\mathrm{Co}-57$}

Co-57 $\left(\mathrm{T}_{1 / 2}=271.79(9)\right.$ days $)$ decays by EC process $(100 \%)$ to Fe-57 (stable) by emitting ten $\gamma$ rays, including two with a branching ratio higher than $10 \%$ and easily detectable (see table 4 ). This radionuclide is fed by the decay of Ni-57, co-produced in the nickel target. Our Co-57 production cross section values are obtained after the complete decay of $\mathrm{Ni}-57\left(\mathrm{~T}_{1 / 2}=\right.$ $35.6(6) \mathrm{h})$.

The general trend gives a maximum around $550 \mathrm{mb}$. Our data are in agreement with this maximum and with the general trend. Some published data give lower values, that can be attributed to the incomplete decay of $\mathrm{Ni}-57$ or to the measurement of independent Co-57 production cross section values. TALYS 1.6 default gives very good results.

\subsubsection{Production of $\mathrm{Co}-58 \mathrm{~m}+\mathrm{g}$}

Co-58 has a metastable state, Co-58m ( $\mathrm{T}_{1 / 2}=9.04$ (11) hours), which decays to its ground state, Co-58g, by emitting a low energy gamma ray $(24.88 \mathrm{keV})$ with a branching ratio lower than $0.04 \%$, not detectable in our experimental conditions. One detectable gamma ray with an energy of 


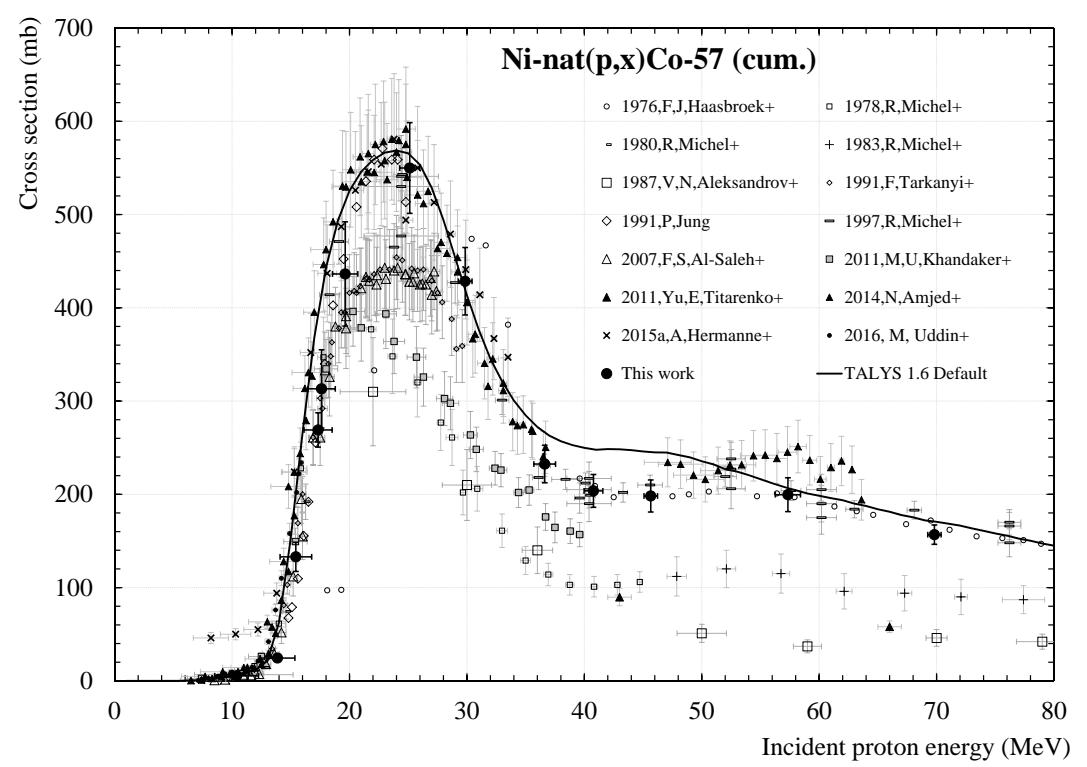

Figure 13: Ni-nat(p,x)Co-57 (cum.) excitation function.

$811.775 \mathrm{keV}(99 \%)$ is associated to the decay of Co-58g $\left(\mathrm{T}_{1 / 2}=70.86(7)\right.$ days). This $\gamma$ line was used to determine its activity. The activity is measured one week after the end of irradiation, assuming that all Co-58m has decayed. The Co-58 cross section values, plotted in figure 14, include the metastable and the ground state production.

There is a good agreement between our values and the literature. However, the maximum value of the cross section around $38 \mathrm{MeV}$ is different between the data sets of Khandaker et al., 2011 and Amjed et al., 2014, in comparison with this work and the values of Hermanne et al., 2015a. The same difference with Khandaker et al. data has been already highlighted for Co-56 production cross section. For this isotope, other data are needed around the maximum of its cross section and above. The TALYS code gives good values whether in shape and amplitude.

\subsubsection{Production of $M n-52 m+g$}

Mn-52 has a metastable and a ground state, both promising for diagnostics (Atcher et al., 1980, Topping et al., 2013). The metastable state Mn-52m $\left(\mathrm{T}_{1 / 2}=21.1(2) \mathrm{min}\right)$ decays by IT $(1.75 \%)$ to its ground state Mn-52g $\left(\mathrm{T}_{1 / 2}=5.591\right.$ (3) days) and by $\beta+$ emission $(98.25 \%)$ to $\mathrm{Cr}-52$ (stable). The ground state Mn-52g decays at $100 \%$ by $\mathrm{CE} / \beta+$ to $\mathrm{Cr}-52$ 


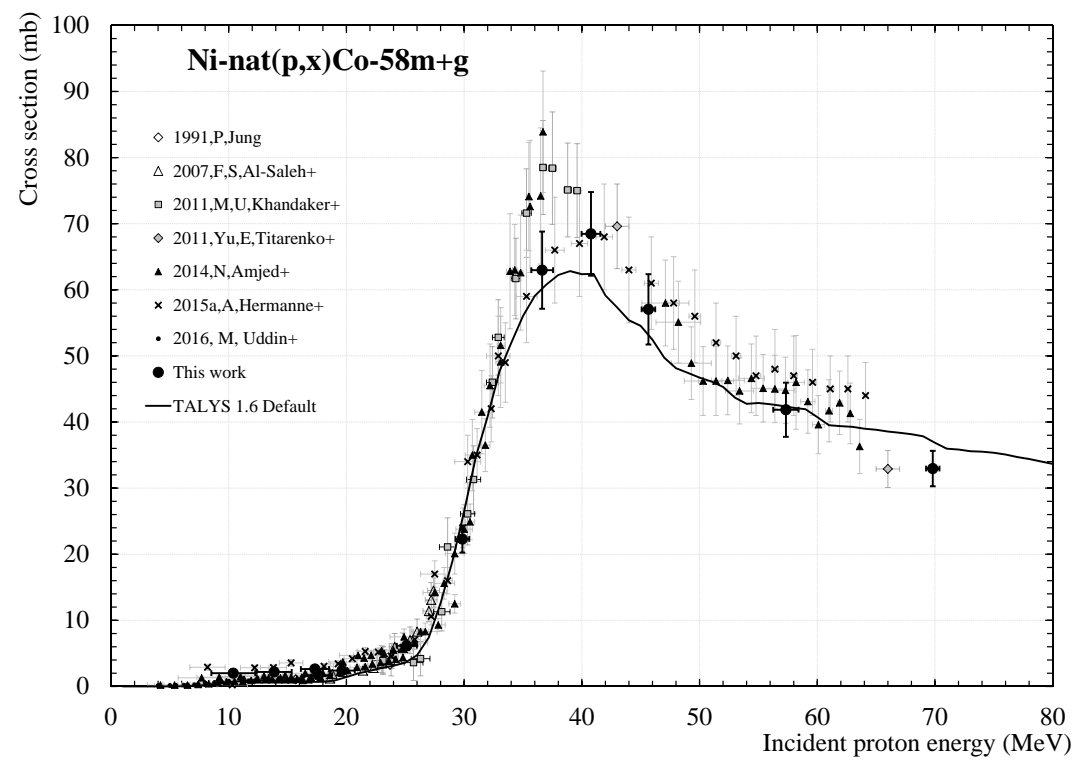

Figure 14: Ni-nat $(\mathrm{p}, \mathrm{x}) \mathrm{Co}-58 \mathrm{~m}+\mathrm{g}$ excitation function.

(stable). Due to its short half-life, this metastable state decayed between the end of irradiation and the activity measurements. This way, we were only able to measure the cumulative activity coming from the direct production of $\mathrm{Mn}-52 \mathrm{~g}$ and the decay of $\mathrm{Mn}-52 \mathrm{~m}$. The related cross section results are plotted in figure 15.

The Mn- $52 \mathrm{~m}+\mathrm{g}$ cross section results show a maximum around $55 \mathrm{MeV}$. Our data are in agreement with Hermanne et al., 2015. Further measurements are needed to better refine the trend, above $65 \mathrm{MeV}$. The TALYS code gives the good shape but underestimates by $50 \%$ from $50 \mathrm{MeV}$.

\subsubsection{Production of $M n-54$}

Mn-54 has a long half-life (312.3 (4) days). It decays by CE process (100 $\%)$ to Cr-54 (stable), emitting one gamma ray (see table 4 ), used to extract Mn-54 activity.

Our results follow those previously published by Michel et al., 1983, Michel et al., 1997 and Titarenko et al., 2011. Once again, TALYS gives the good trend but underestimates the experimental results. 


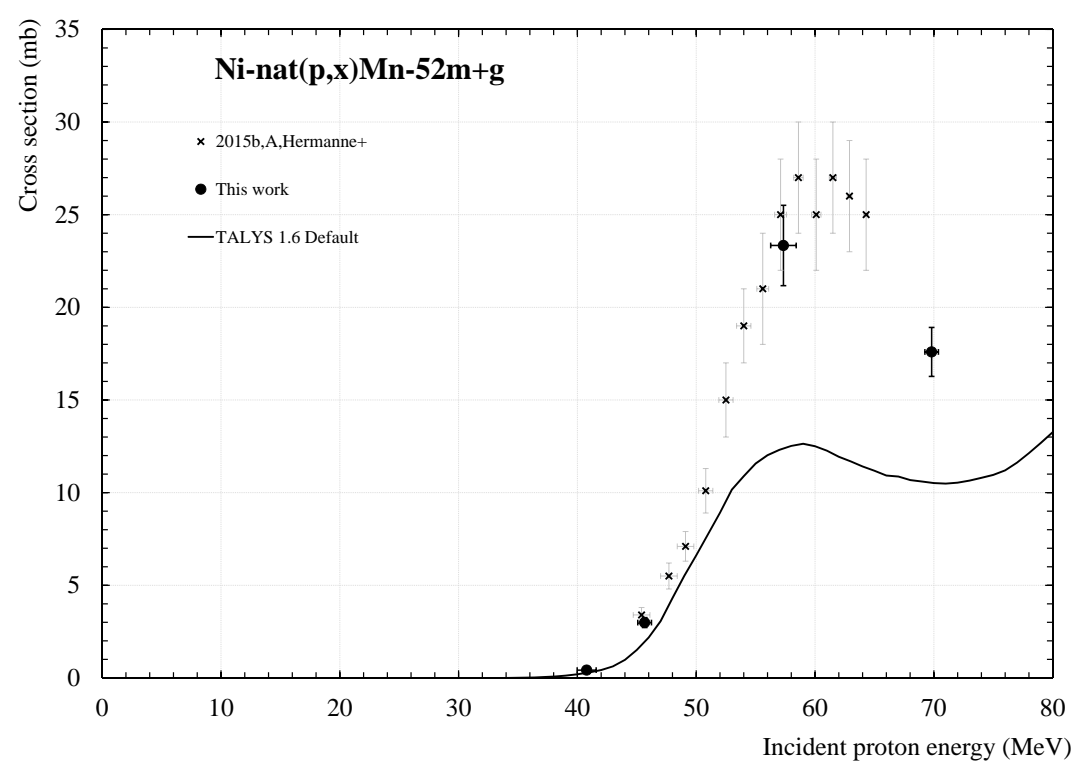

Figure 15: Ni-nat $(\mathrm{p}, \mathrm{x}) \mathrm{Mn}-52 \mathrm{~m}+\mathrm{g}$ excitation function.

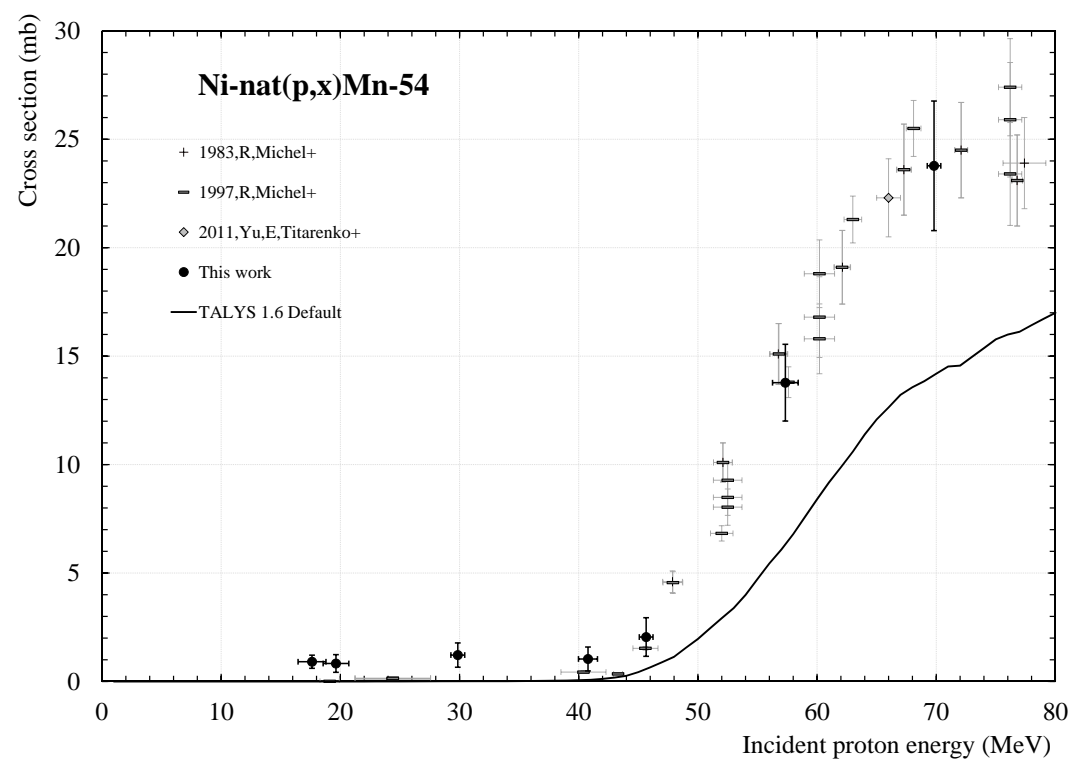

Figure 16: Ni-nat(p,x)Mn-54 excitation function.

\subsection{Proton induced reactions on natural copper}

The IAEA has defined recommended cross section values for the $\mathrm{Cu}$ nat $(\mathrm{p}, \mathrm{x}) \mathrm{Zn}-62,65$, Co-56 reactions and proposes the $\mathrm{Cu}-\mathrm{nat}(\mathrm{p}, \mathrm{x}) \mathrm{Co}-58$ as 
potential additional monitor reaction (Tárkányi et al., 2012-2016). In this study, the $\mathrm{Cu}-n a t(\mathrm{p}, \mathrm{x}) \mathrm{Zn}-62$ reaction has been used as monitor between 46 $\mathrm{MeV}$ and $60 \mathrm{MeV}$, and the $\mathrm{Cu}$-nat(p,x)Co-56 reaction has been used as monitor reaction above $60 \mathrm{MeV}$. The physical characteristics of the radionuclides produced in the copper foils are listed in table 6 and their associated production cross section values are presented in table 7 .

\subsubsection{Production of $Z n-62$}

Zn-62 is of medical interest as it produces, by decay, the PET imaging agent $\mathrm{Cu}-62$ (Okazawa et al., 1995). In addition, the Cu-nat(p,x)Zn-62 reaction is defined as monitor reaction with recommended values defined by the IAEA (Tárkányi et al., 2001). Zn-62 has a half-life of 9.1786 (13) hours and decays by EC/ $\beta+$ process $(100 \%)$ to $\mathrm{Cu}-62\left(\mathrm{~T}_{1 / 2}=9.74\right.$ (2) minutes), by emitting different detectable $\gamma$ lines (see table 6 ). New data have been obtained (see figure 17) for Zn-62 production cross section using the Tinat(p,x)V-48, Ni-nat(p,x)Ni-57 and Cu-nat(p,x)Co-56 monitor reactions.

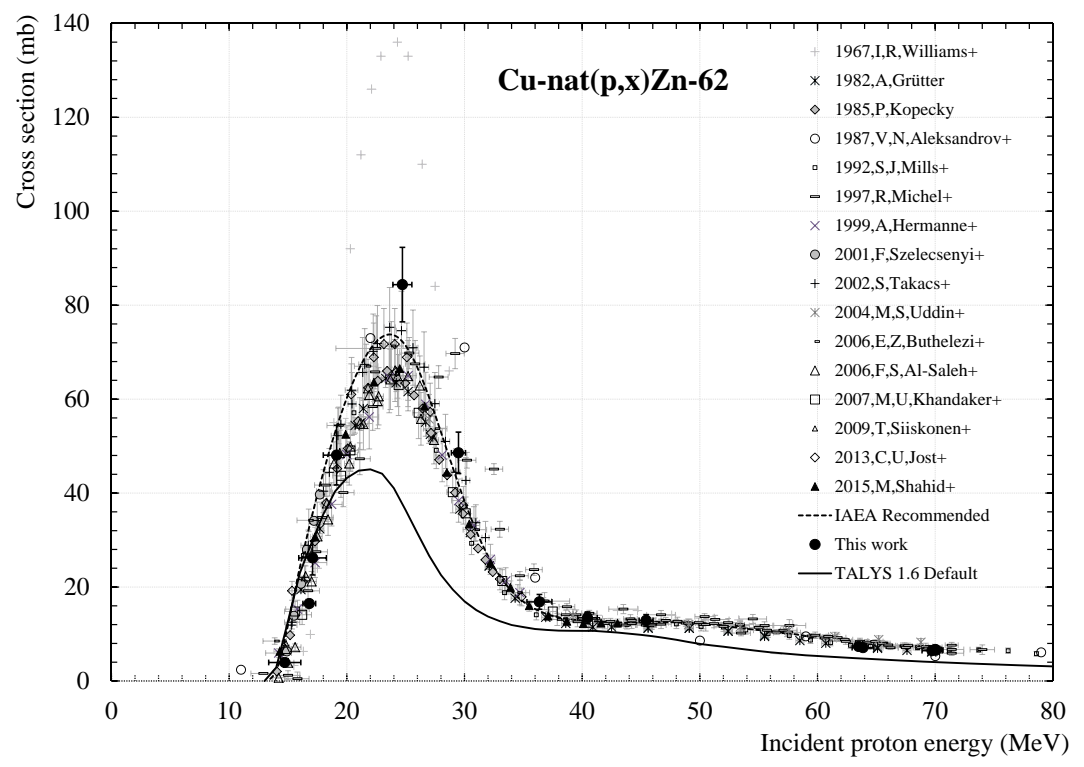

Figure 17: Cu-nat(p,x)Zn-62 excitation function.

Our values are in overall good agreement with the literature and follow the recommended cross section, except our maximum that is $10 \%$ to $20 \%$ higher depending on the dataset used for comparison. Due to the spread 
between the dataset for the quantification of this maximum, further values have to be obtained to better estimate it. TALYS 1.6 Default results give the good trend but underestimate the cross section amplitude.

\subsubsection{Production of $\mathrm{Zn-65}$}

Zn-65 ( $\mathrm{T}_{1 / 2}=244.26(26)$ days $)$ decays by EC/ $\beta+$ process $(100 \%)$ to $\mathrm{Cu}-65$ (stable) by emitting three $\gamma$ rays. Among these $\gamma$ lines, the one at $1115.546 \mathrm{keV}(50.60$ (24) \%) was detectable by our device in our experimental conditions. Our new cross section results are plotted in figure 18.

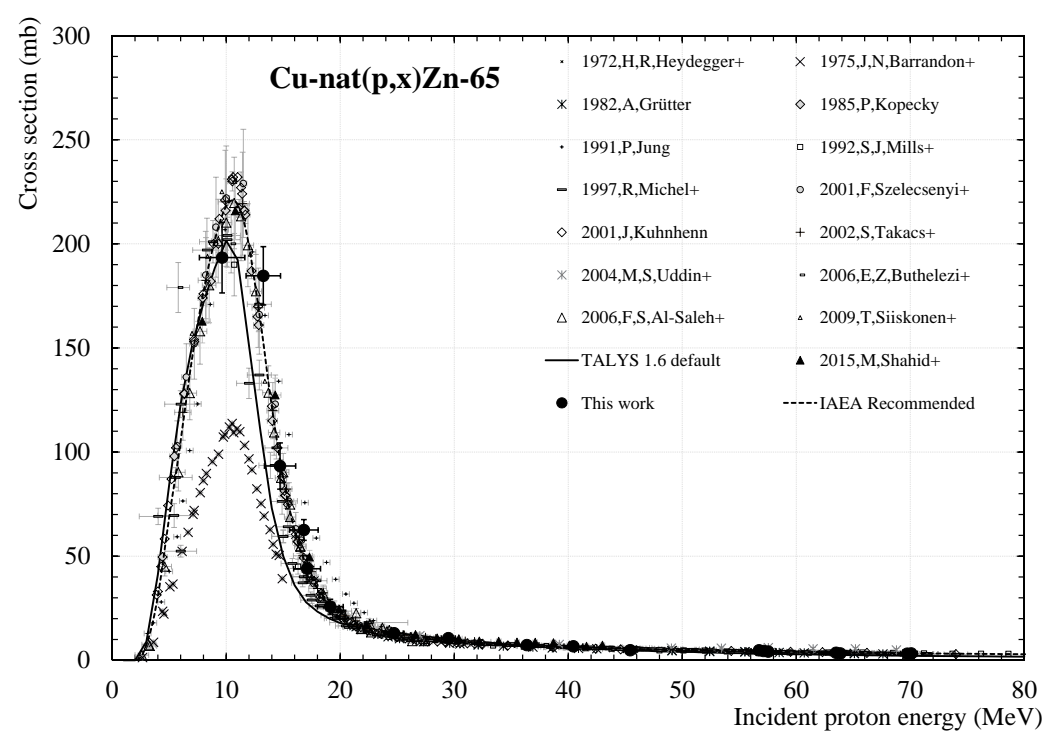

Figure 18: Cu-nat $(\mathrm{p}, \mathrm{x}) \mathrm{Zn}-65$ excitation function.

Our data points are in agreement with the literature and the recommended cross section. Between 8 and $18 \mathrm{MeV}$, TALYS values are too low compared to the experimental ones.

\subsubsection{Production of $\mathrm{Co}-56$}

The physical characteristics of Co-56 have been presented in part 3.2.4, and are listed in table 6 . It is considered as independent because no Ni-56 has been detected in the copper targets. The $\mathrm{Cu}-\mathrm{nat}(\mathrm{p}, \mathrm{x}) \mathrm{Co}-56$ reaction has a recommended cross section defined by the IAEA committee members.

Three data points have been obtained in this work between 56 and 58 $\mathrm{MeV}$, using Zn-62 as monitor. Our data are plotted in figure 19, with data 
from the literature. They follow the recommended values. Data from Shahid et al., 2016 are in strong disagreement with the other ones, due to recoil activity coming from the nickel foils, which were placed before the copper foils. No additional data seems needed in the $40-70 \mathrm{MeV}$ energy range for this reaction. However, TALYS 1.6 Default is not able to reproduce this excitation function but gives the good trend.

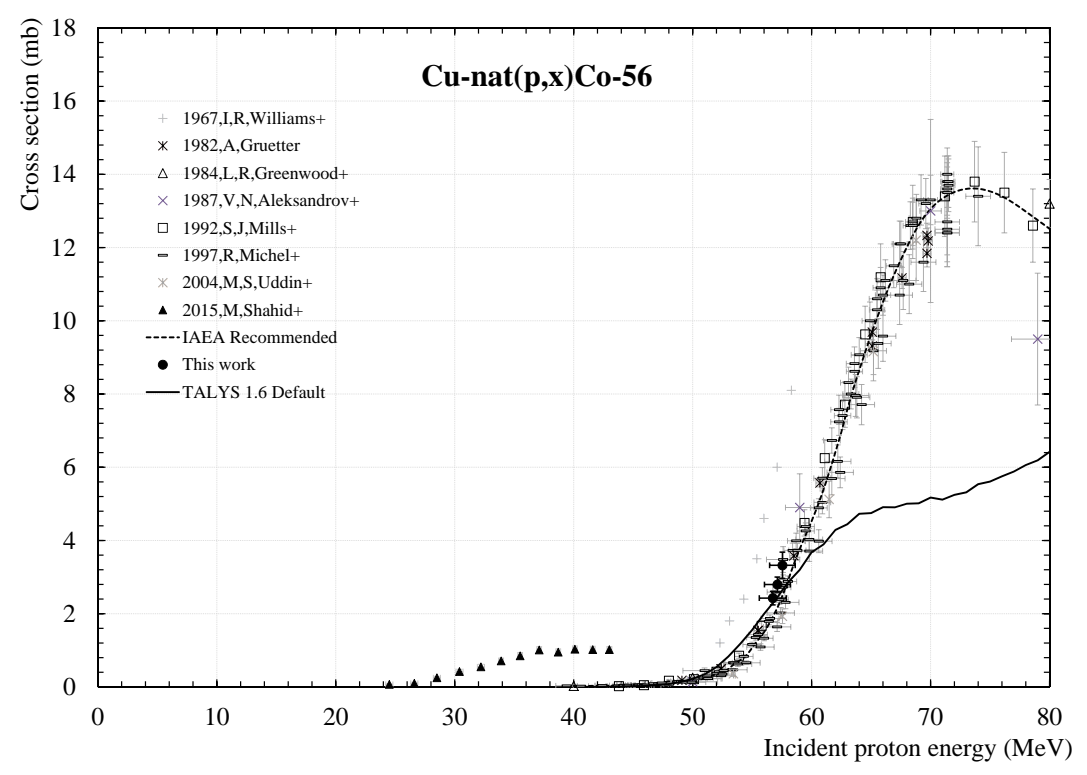

Figure 19: Cu-nat(p,x)Co-56 excitation function.

\subsubsection{Cumulative production of $\mathrm{Co}-57$}

The physical characteristics of Co- 57 have been presented in part 3.2.5, and are listed in table 6 . The production cross section values are obtained after the total decay of Ni-57 co-produced in the target (see part 3.3.9).

Our data, plotted in figure 20, follow the trend of Grütter, 1982, Mills et al., 1992, Michel et al.,1997 and Yashima et al., 2002. Data published in William and Fulmer, 1967, Greenwood and Smither, 1984 and Aleksandrov et al., 1987 are not in agreement with the general behaviour. As for Co-56, the values published by Shahid et al., 2015, are contaminated by the Co-57 recoil nuclei produced in the nickel foils. TALYS results do not agree with the experimental ones. 


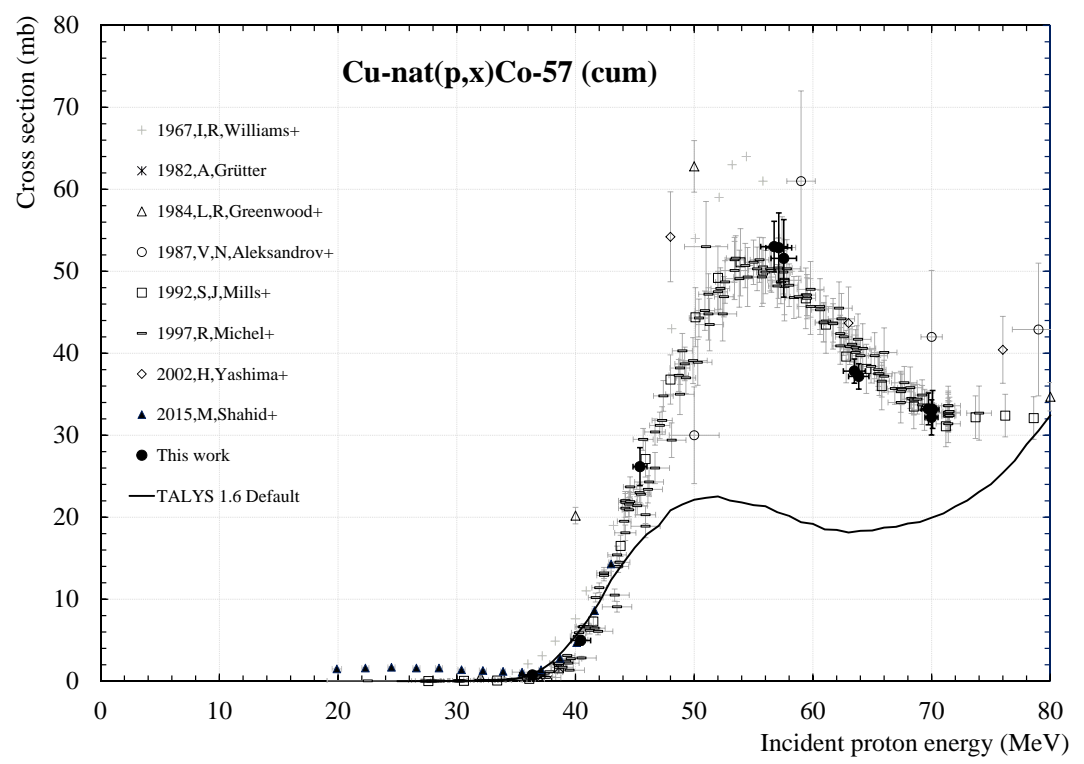

Figure 20: Cu-nat(p,x)Co-57 (cum.) excitation function.

\subsubsection{Production of $\mathrm{Co}-58 \mathrm{~m}+\mathrm{g}$}

The physical characteristics of Co-58 have been presented in part 3.2.6, and are listed in table 6 . Our cumulative production cross section values for Co- $58 \mathrm{~m}+\mathrm{g}$ production in copper are presented in table 5 and plotted in figure 21.

Our points are in good agreement with the work published by Grütter, 1982, Kopecky, 1985 and Shahid et al., 2015, but not with Greenwood and Smither, 1984 and Yashima et al., 2002 below $55 \mathrm{MeV}$. The maximum of the cross section, reproduces by our points around $40 \mathrm{MeV}$, is in agreement with the values of Grütter, 1982 and Shahid et al., 2015. However, we have to take into account some Co-58 recoil nuclei in the experiment of Shahid et al., 2015. The maximum plotted by the data of Greenwood and Smither, 1984, are $20 \%$ higher than our value. The TALYS code gives the good trend but underestimates the amplitude of the cross section in comparison with the experimental values.

\subsubsection{Production of $\mathrm{Co}-60 \mathrm{~m}+\mathrm{g}$}

The metastable state Co-60m, with a half-life of 10.467 (6) min, decays by IT process $(99.76 \%)$ to its ground state Co-60g and by $\beta$ - emission $(0.24$ 


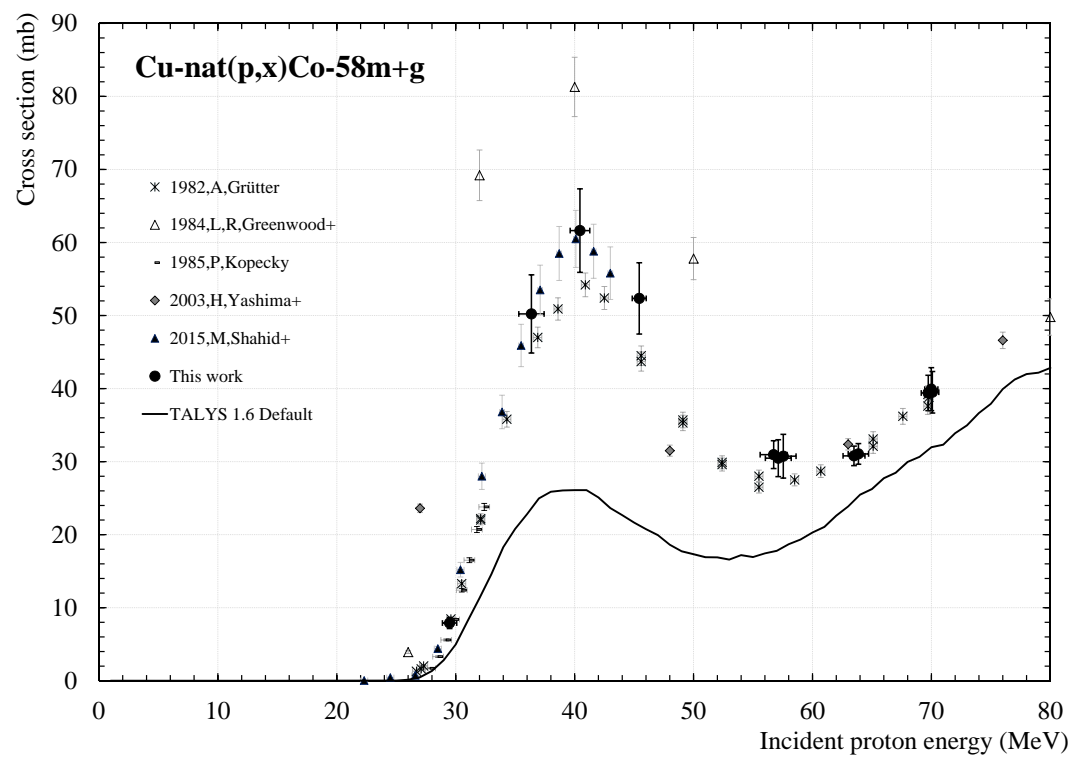

Figure 21: Cu-nat $(\mathrm{p}, \mathrm{x}) \mathrm{Co}-58 \mathrm{~m}+\mathrm{g}$ excitation function.

$\%$ ) to Ni-60 (stable). Co-60g has a long half-life of 5.2714 (5) years and is a $100 \% \beta$ - emitter. Due to the short half-life of Co- $60 \mathrm{~m}$, we were only able to determine the cumulative activity of both states: Co- $60 \mathrm{~m}+\mathrm{g}$. The related cross section values are plotted in figure 22 .

Only 4 to $15 \mathrm{~Bq}$ of Co-60 were measured in our targets, in our experimental conditions. The values obtained by Greenwood and Smither, 1984, are also cumulative and expressed with $5 \%$ of uncertainty. Our data are compatible with the experiment of Shahid et al., 2015. No uncertainty is specified on Grütter, 1982 values. TALYS gives a quite good trend but underestimated.

\subsubsection{Production of $\mathrm{Cu}-61$}

$\mathrm{Cu}-61$ is among the list of copper isotopes well suitable for PET imaging (Williams et al., 2005). Cu-61 has a half-life of 3.333 (5) hours and decays by $\mathrm{EC} / \beta+$ process to Ni-61 (stable). The gamma lines used to determine the $\mathrm{Cu}-61$ activity are listed in table 6 . The production cross section values are presented in table 5 and plotted in figure 23.

Our data follow the general trend. Our values are especially in agreement with Mills et al., 1992 in the whole energy range. Our data are also in good agreement with Michel et al., 1997 and Grütter, 1982, within the error bars. 


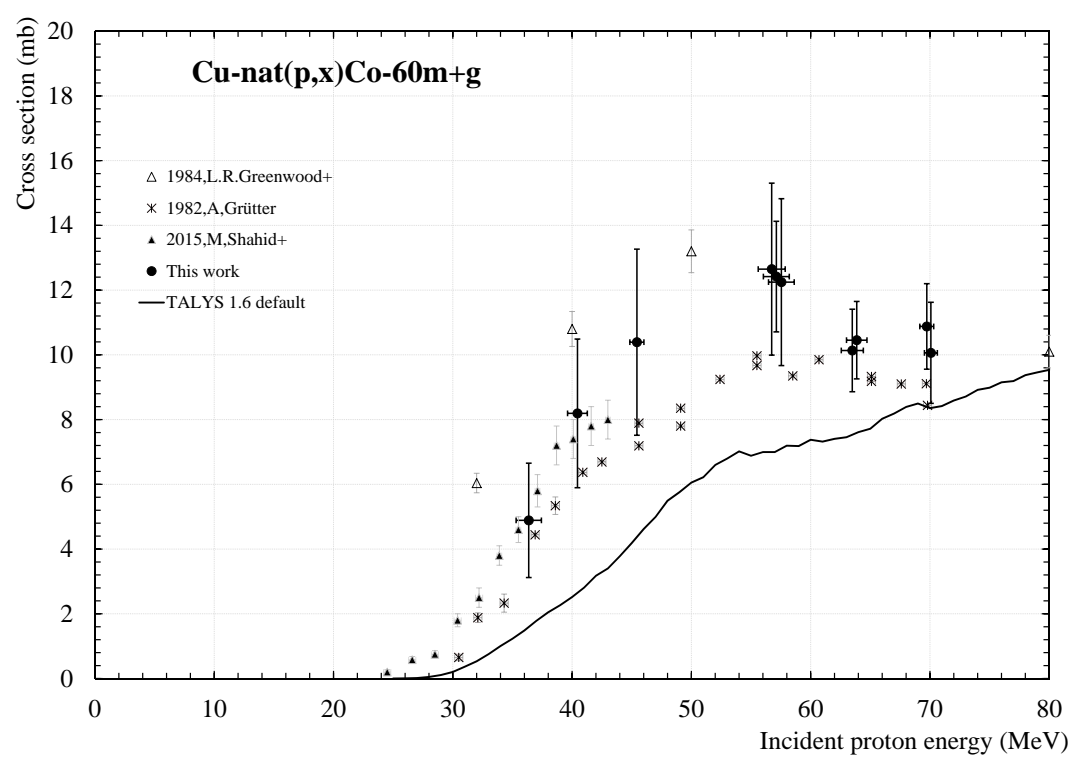

Figure 22: Cu-nat $(\mathrm{p}, \mathrm{x}) \mathrm{Co}-60 \mathrm{~m}+\mathrm{g}$ excitation function.

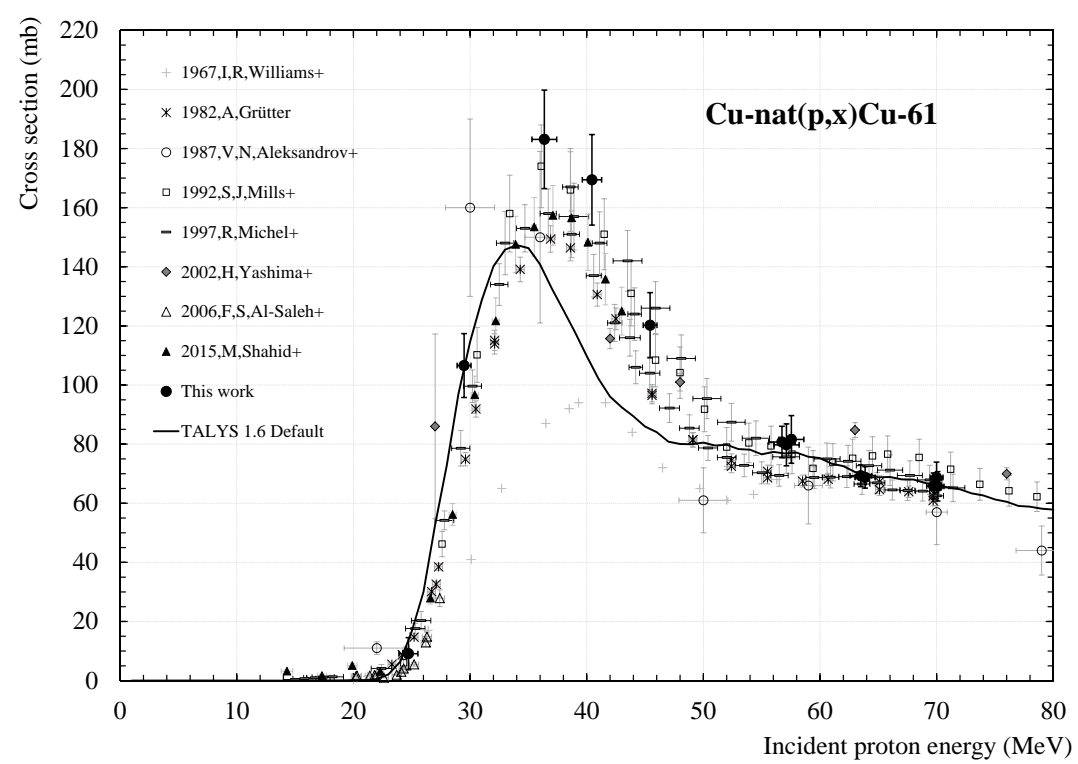

Figure 23: $\mathrm{Cu}-\mathrm{nat}(\mathrm{p}, \mathrm{x}) \mathrm{Cu}-61$ excitation function.

TALYS gives good results except in the $35-50 \mathrm{MeV}$ energy range, where the 
values are too low in comparison with the experimental results.

\subsubsection{Production of $\mathrm{Cu}-64$}

$\mathrm{Cu}-64$ is a $\beta+(61.5 \%)$ and $\beta$ - $(38.5 \%)$ emitter, suitable for PET imaging (Anderson and Ferdani, 2009), dosimetry and possibly for therapy (Bryan et al., 2011). It has a half-life of 12.700 (2) hours and emits one gamma line at $1345.84 \mathrm{keV}$ with a low branching of 0.473 (10) \%.

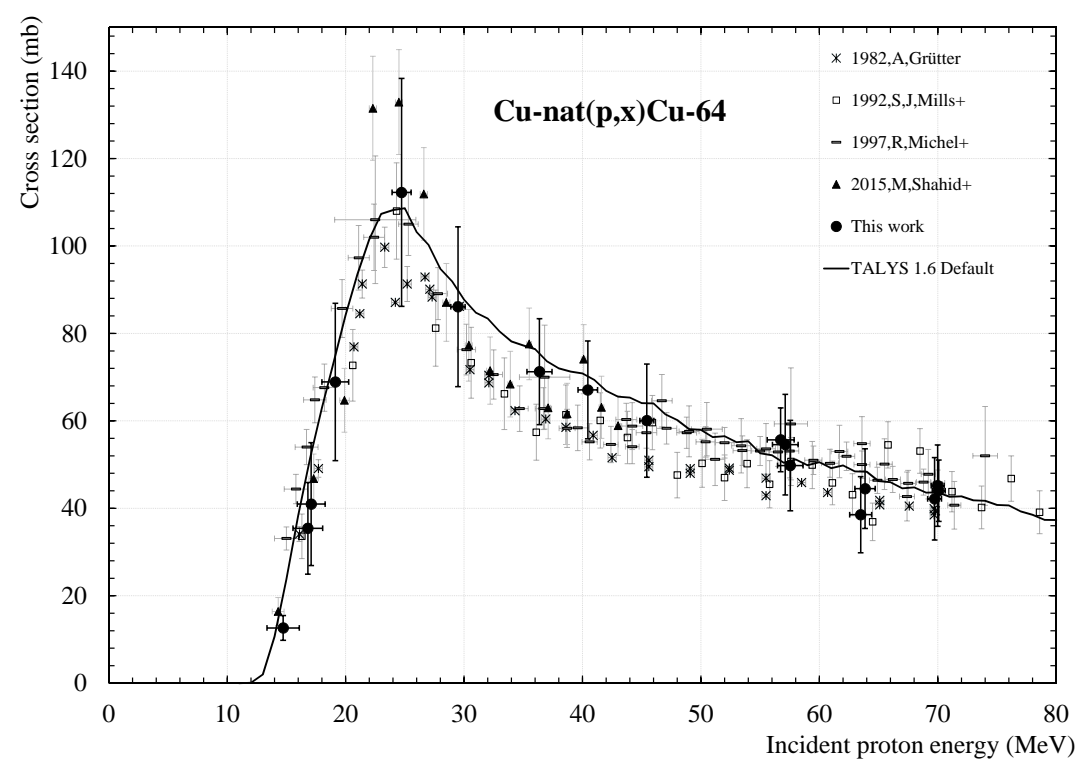

Figure 24: Cu-nat(p,x)Cu-64 excitation function.

Our data are obtained with an uncertainty of $23 \%$ in average, due to the low branching ratio of the emitted $\gamma$ ray. Our results are plotted in figure 24 . They follow the general trend and are especially in good agreement with the work of Michel et al., 1997. TALYS 1.6 Default results are in good agreement with our work.

\subsubsection{Production of Ni-57}

The physical characteristics of Ni-57 have been presented in part 3.2.1, and are listed in table 6 .

Our new data, plotted in figure 25, are in agreement with the general trend drawn by the literature data, and especially with the results of Mills et al., 1982 and the large set of data of Michel et al., 1997. The results 


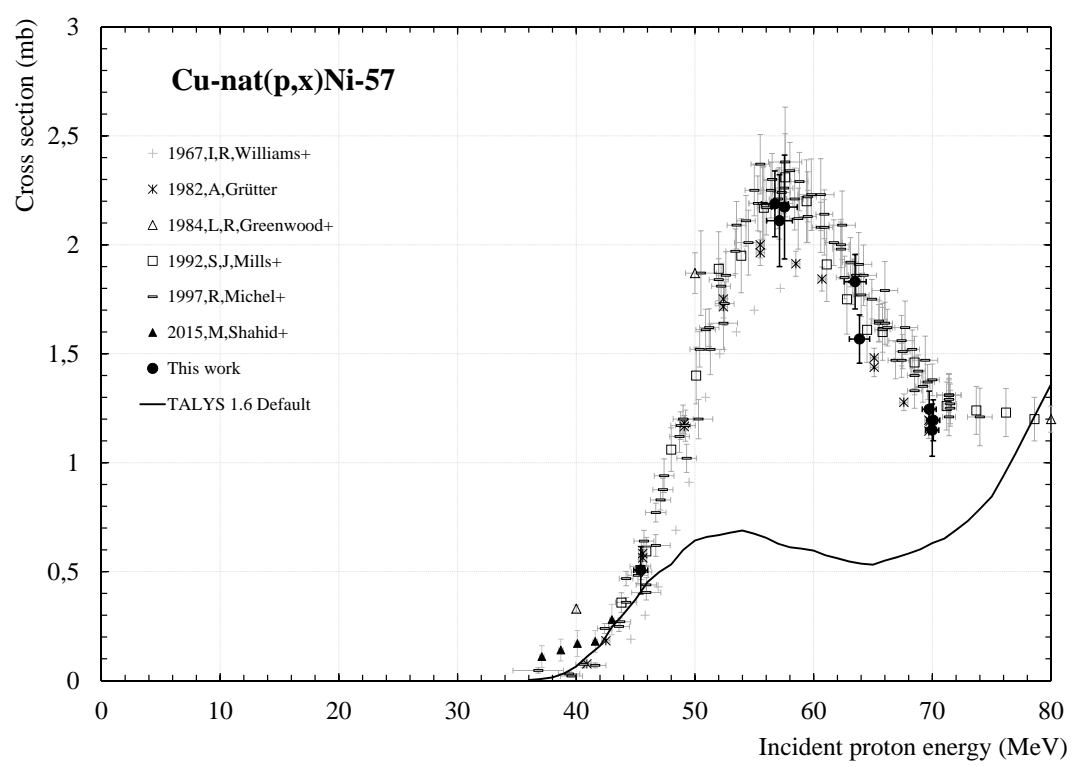

Figure 25: Cu-nat(p,x)Ni-57 excitation function.

of Williams and Fulmer, 1967 and Grütter, 1982 are slightly lower. Those published in Greenwood and Smither, 1984, are shifted. The effect of the recoil activity in the experimen of Shahid et al., 2015 is visible in this plot. TALYS 1.6 Default is not able to reproduce the trend.

\subsubsection{Production of $M n-54$}

The physical characteristics of Mn-54 have been stated in part 3.2.8, and are listed in table 6 .

This radionuclide is not easily detectable in the copper target due to its long half-life $\left(\mathrm{T}_{1 / 2}=312.3\right.$ (4) days) and low production cross section (see figure 26). All data are in good agreement, even if the results published in Grütter, 1982, and Yashima et al., 2009, between 60 and $70 \mathrm{MeV}$, are slightly lower. TALYS doesn't give satisfactory results.

\section{Conclusion}

Experimental data have been obtained on the production of several radionuclide induced by protons on natural titanium (part 3.1), nickel (part 3.2) and copper (part 3.3). Results of this work fit with the literature and allow to add information in databases for proton induced reactions up to 70 


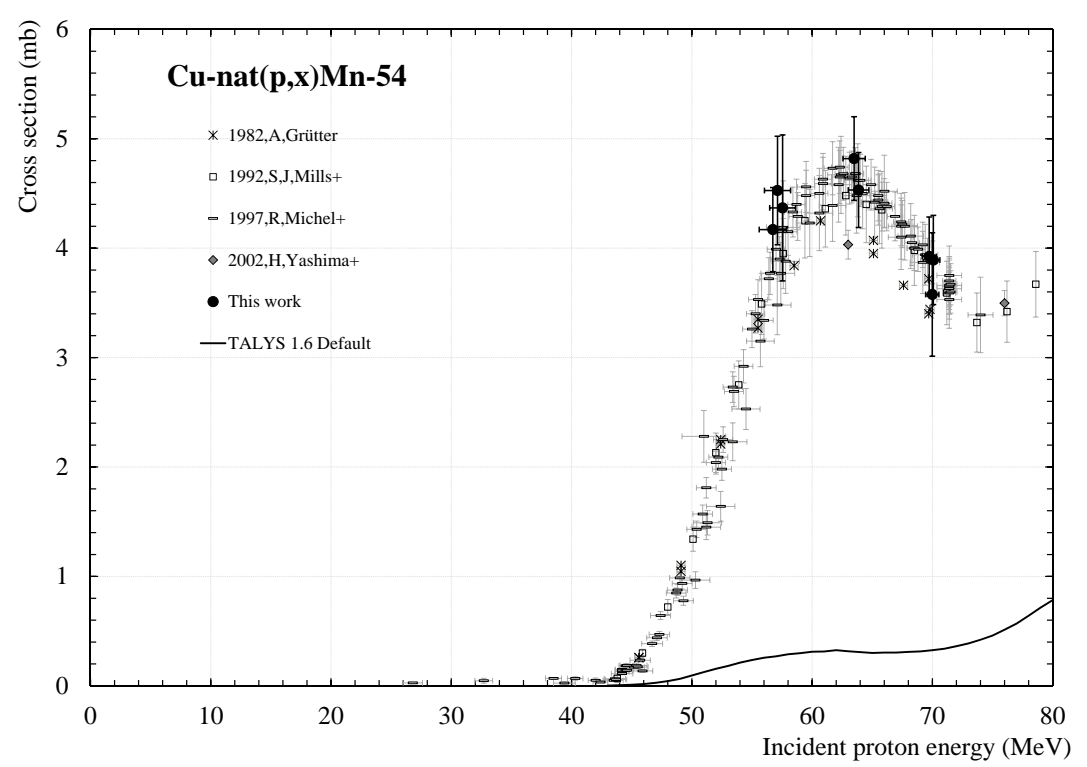

Figure 26: Cu-nat(p,x)Mn-54 excitation function.

$\mathrm{MeV}$. These data have been extracted using a relative calculation through the use of monitor reactions from IAEA recommended values.

Some radionuclides produced during our experiments are of medical interest (i.e. Sc-47, Cu-64 ...). Other ones are good candidates for monitor reactions. Some new monitor reactions have been highlighted by the IAEA including Ti-nat(p,x)Sc-46, Ni-nat(p,x)Co-56,58 and Cu-nat(p,x)Co-58. Relative cross section data have been extracted in this work for these previous reactions. Ti-nat $(\mathrm{p}, \mathrm{x}) \mathrm{Sc}-44 \mathrm{~m}, \mathrm{Sc}-47$ and $\mathrm{Cu}-\mathrm{nat}(\mathrm{p}, \mathrm{x}) \mathrm{Ni}-57, \mathrm{Co}-57$ excitation functions have a large set of data available, as well as the Ni-nat(p,x)Ni-57 and $\mathrm{Cu}-\mathrm{nat}(\mathrm{p}, \mathrm{x}) \mathrm{Zn}-62$ reactions for which the recommended values could be extended up to $80 \mathrm{MeV}$.

Our data are especially in good agreement with the values published by Mills et al. in 1992 and with the large set of data published by Michel et al. in 1997. Our values contribute to the description of a large number of excitation functions. However, in the case of monitor reactions, there is a real need of absolute data. In this frame, we are currently working on a new experimental device in collaboration with the mechanical department of the SUBATECH laboratory. This device will allow stack irradiations in vacuum and will contain a Faraday cup for accurate intensity measurements. It will 
be placed at the end of the ARRONAX beam lines and will allow to get absolute experimental cross section data.

All data have been compared to the results of the TALYS 1.6 code using default models. TALYS shows good results for proton induced reactions on nickel. However, with copper and titanium as targets, it gives a good trend in overall but too often over- or under-estimates the cross section in comparison with the experimental values.

\section{Acknowledgments}

Authors would like to thanks all the GIP ARRONAX team and mechanical department team of SUBATECH for their contribution. The ARRONAX cyclotron is a project promoted by the Regional Council of Pays de la Loire financed by local authorities, the French government and the European Union. This work has been, in part, supported by a grant from the French National Agency for Research called 'Investissements d'Avenir', Equipex Arronax-Plus $\mathrm{n}^{o}$ ANR-11-EQPX-0004 and Labex n ${ }^{o}$ ANR-11-EQPX-0018-01.

\section{References}

Al-Saleh, F.S., Al Mugren, K.S., Azzam, A. Excitation functions of (p,x) reactions on natural nickel between proton energies of 2.7 and $27.5 \mathrm{MeV}$, Applied Radiation and Isotopes, 2007, Volume 65, Issue 1, Pages 104-113.

Aleksandrov, V.N., Semenova, M.P. and Semenov, V.G. Production Cross Section of Radionuclides in $(\mathrm{p}, \mathrm{x})$ Reactions at Copper and Nickel Nuclei, Soviet. Atomic Energy, 1987, 62 (6), 478-81.

Alharbi, A.A., Alzahrani, J., and Azzam, A. Activation cross-section measurements of some proton induced reactions on $\mathrm{Ni}$, Co and Mo for proton analysis (PAA) purposes, Radiochimica Acta, 2011, 99 (12), 763-70.

Amjed, N., Tárkányi, F., Hermanne, A., Ditrói, F., Takács, S., Hussain, M. Activation cross-section of proton induced reactions on natural $\mathrm{Ni}$ up to $65 \mathrm{MeV}$., Applied Radiation and Isotopes, 2014, 92, 73-84.

Anderson, C.J. and Ferdani, R. Copper-64 radiopharmaceuticals for PET imaging of cancer: advances in preclinical and clinical research, Cancer Biother Radiopharm., 2009, 24(4), 379-93. doi: 10.1089/cbr.2009.0674.

Atcher R.W., Friedman, A.M., Huizenga, J.R., Rayudu, G.V., Silverstein, E.A., Turner, D.A. Manganese-52m, a new short-lived, generator-produced 
radionuclide: a potential tracer for positron tomography, J Nucl Med., 1980, $21(6), 565-9$.

Barrandon, J.N., Debrun, J.L., Kohn, A., Spear, R.H. 'E)tude du dosage de $\mathrm{Ti}, \mathrm{V}, \mathrm{Cr}, \mathrm{Fe}, \mathrm{Ni}, \mathrm{Cu}$ et $\mathrm{Zn}$ par activation avec des protons d'énergie limitée à $20 \mathrm{MeV}$, Nuclear Instruments and Methods, 1975, Volume 127, Issue 2, Pages 269-78.

Bennett, M.E, Mayorov, D.A., Chapkin, K.D., Alfonso, M.C., Werke, T.A. and Folden C.M. Measurement of the natLu(p,x)175Hf excitation function, Nuclear Instruments and Methods in Physics Research Section B: Beam Interactions with Materials and Atoms, 2012, 276, 62-5.

Blessing, G., Bräutigam, W., Böge, H.G., Gad, N., Scholten, B., and Qaim, S.M. Internal irradiation system for excitation function measurement via the stacked-foil technique, Appl. Radiat. Isot., 1995, 955, 46-9.

Bringas, F., M. T. Yamashita, I. D. Goldman, P. R. Pascholati and V. Sciani. Measurement of Proton-Induced Reaction Cross Sections in Ti, $\mathrm{Ni}$ and Zr near the Threshold, AIP Conf. Proc., 2005, 769 (1), 1374 - 7, DOI:10.1063/1.1945260.

Brodzinski, R.L., Rancitelli, L.A., Cooper, J.A., and Wogman, N.A. HighEnergy Proton Spallation of Titanium. Phys. Rev. C, 1971, 4, 1250.

Bryan, J.N., Jia, F., Mohsin, H., Sivaguru, G., Anderson, C.J., Miller, W.H., Henry, C.J. and Lewis, M.R. Monoclonal antibodies for copper-64 PET dosimetry and radioimmunotherapy, Cancer Biology and Therapy, 2011, Volume 11, Issue 12, pages 1001-7.

Buthelezi, E.Z., Nortier, F.M. and Schroeder, I.W. Excitation functions for the production of $82 \mathrm{Sr}$ by proton bombardment of natRb at energies up to $100 \mathrm{MeV}$, Applied Radiation and Isotopes, 2006, Volume 64, Issue 8, Pages 915-24.

De Reuck, J., Patrick Santens,P., Strijckmans, K. and Lemahieu, I., on behalf of the European Task Force on Age-Related White Matter Changes. Cobalt-55 positron emission tomography in vascular dementia: significance of white matter changes, Journal of the Neurological Sciences, 2001, 193, 1-6.

Duchemin, C., Guertin, A., Haddad, F., Michel, N., Métivier, V. Production of medical isotopes from a thorium target irradiated by light charged particles up to $70 \mathrm{MeV}$. Phys. Med. Biol., 2015a, 60, 931-46.

Duchemin, C., Guertin, A., Haddad, F., Michel, N., Métivier, V. Production of scandium-44m and scandium-44g with deuterons on calcium-44: cross section measurements and production yield calculations. Phys. Med. 
Biol., 2015b, 60, 6847-64.

Ekström, L.F., and Firestone, R.B., 2004. Information extracted from the Table of Radioactive Isotopes, version 2.1.

Fink, D., Sisterson, J., Vogt, S., Herzog, G., Klein, J., Middleton, R., Koehler, A. and Magliss, A. Production of 41Ca and K, Sc and V short-lived isotopes by the irradiation of $\mathrm{Ti}$ with 35 to $150 \mathrm{MeV}$ protons: applications to solar cosmic ray studies, Nuclear Instruments and Methods in Physics Research Section B: Beam Interactions with Materials and Atoms, 1990, Volume 52, Issues 3-4, Pages 601-7.

FitzPeaks Gamma Analysis and Calibration Software version 3.66, produced by JF Computing Services (UK), based on methods presented in Nucl.Instrum. and Methods, 1981, 190, 89-99, describing the program SAMPO80 of the Helsinki University of Technology, Finland.

Furukawa, M., Shinohara, A., Narita, M. and Kojima, S. Production of cosmic-ray induced radionuclides, $49 \mathrm{~V}$ and $59,63 \mathrm{Ni}$ from $\mathrm{Fe}$, Co and $\mathrm{Ni}$ irradiated with protons up to Ep=40 MeV, Univ.Tokyo,Inst.f.Nucl.Study, 1990, Annual Report, 1989, 32.

Greenwood, L.R. and Smither, K.R. Measurement of $\mathrm{Cu}$ spallation cross sections at IPNS, U.S. Dept.of Energy, Fusion Energy Series, 1984, Vol.18, No.0046, 11.

Grütter, A. Excitation functions for radioactive isotopes produced by proton bombardment of $\mathrm{Cu}$ and $\mathrm{Al}$ in the energy range of 16 to $70 \mathrm{MeV}$, Nuclear Physics A, 1982, Volume 383, Issue 1, Pages 98-108.

Haddad, F., Ferrer, L., Guertin, A., Carlier, T., Michel, N., Barbet, J., Chatal, J.F. Arronax a high-energy and high-intensity cyclotron for nuclear medicine, Eur. J. Nucl. Med. Mol. Imaging, 2008, 35, 1377-87.

Haasbroek F.J., Steyn J., Neirinckx R.D., Burdzik G.F., Cogneau M. and Wanet P. Excitation Functions and Thick Target Yields For Radioisotopes Induced in Natural Mg, Co, Ni and Ta By Medium Energy Protons, Council for scientific and industrial research, 1976, CSIR research report FIS89, ZA7700031.

Hermanne, A., Szelecsényi, F., Sonck, M., Takács, S., Tárkányi, F. and Van den Winkel, P. New cross section data on68Zn(p, 2n)67Ga andnatZn(p,xn)67Ga nuclear reactions for the development of a reference data base, Journal of Radioanalytical and Nuclear Chemistry, 1999, Volume 240, Issue 2, pp 623-630.

Hermanne, A., Adam Rebeles, R., Tárkányi, F., Takács, S. Excitation functions of proton induced reactions on natOs up to $65 \mathrm{MeV}$ : Experiments and comparison with results from theoretical codes. Nuclear Instruments and 
Methods in Physics Research Section B: Beam Interactions with Materials and Atoms, Volume 345, 15 February 2015a, Pages 5868.

Hermanne, A., Adam Rebeles, R., Tárkányi, F., Takács, S., Ditrói, F. Proton and deuteron induced reactions on natGa: Experimental and calculated excitation functions. Nuclear Instruments and Methods in Physics Research B 359 (2015b) 145154.

Huclier-Markai, S., Sabatié, A., Ribet, S., Kubicek, V., Paris, M., Vidaud, C., Hermann, P., Cutler, C.S. Chemical and biological evaluation of scandium(III)-polyaminopolycarboxylate complexes as potential PET agents and radiopharmaceuticals, Radiochim. Acta, 2011, 99, 653-662.

IAEA, International Atomic Energy Agency. Nuclear Data Service, website: www-nds.iaea.org/. Last Updated: 06-January-2015.

Jansen, H., Van der Naalt, J., Van Zomeren, A.H., Paans, A., Veenma-van der Duin, L., Hew, J.M., Pruim, J., Minderhoud, J.M. and Korf, J. Cobalt55 positron emission tomography in traumatic brain injury: a pilot study, Journal of Neurology, Neurosurgery, and Psychiatry, 1996, 60, 221-224.

Jost, C.U., Griswold, J.R., Bruffey, S.H., Mirzadeh, S., Stracener, D.W. and Williams, C.L. Measurement of cross sections for the 232Th(p,4n)229Pa reaction at low proton energies, AIP Conf. Proceedings, 2013, 1525 (1), $520-4$.

Jung, P. Cross sections for the production of helium and long- living radioactive isotopes by protons and deuterons, Conf.on Nucl.Data for Sci.and Technol., 1991, 352-4.

Khandaker, M.U., Kim, K., Lee M.W., Kim K.S., Kim G.N., Cho, Y.S. and Lee, Y.O. Investigations of the natTi $(\mathrm{p}, \mathrm{x}) 43,44 \mathrm{~m}, 44 \mathrm{~g}, 46,47,48 \mathrm{Sc}, 48 \mathrm{~V}$ nuclear processes up to $40 \mathrm{MeV}$, presented at the 6th International Conference on Isotopes, Applied Radiation and Isotopes, 2009, 67 (7-8), Pages 1348-1354.

Khandaker, M.U., Kim, K., Lee, M., Kim, K.S. and Kim, G. Excitation functions of $(\mathrm{p}, \mathrm{x})$ reactions on natural nickel up to $40 \mathrm{MeV}$, Nuclear Instruments and Methods in Physics Research Section B: Beam Interactions with Materials and Atoms, 2011, 269 (10), 1140-1149.

Kinsey R.R. et al., The NUDAT/PCNUDAT Program for Nuclear Data, paper submitted to the 9th International Symposium of Capture GammaRay Spectroscopy and Related Topics, Budapest, Hungary, October 1996. Data extracted from the NUDAT database, version 2.6.

Koning, A.J., Rochman, D. Modern nuclear data evaluation with the TALYS code system, Nucl. Data Sheets, 2012, 113, 2841. TALYS 1.6 available online http://www.talys.eu/. 
Kopecky, P. Proton beam monitoring via the $\mathrm{Cu}(\mathrm{p}, \mathrm{x}) 58 \mathrm{Co}, 63 \mathrm{Cu}(\mathrm{p}, 2 \mathrm{n})$ $62 \mathrm{Zn}$ and $65 \mathrm{Cu}(\mathrm{p}, \mathrm{n}) 65 \mathrm{Zn}$ reactions in copper. The International Journal of Applied Radiation and Isotopes, 1985, Volume 36, Issue 8, Pages 657-661.

Kopecky, P., Szelecsényi, F., Molnár, T., Mikecz, P. and Tárkányi, F. Excitation functions of $(\mathrm{p}, \mathrm{xn})$ reactions on natTi: Monitoring of bombarding proton beams, Applied Radiation and Isotopes, 1993, 44 (4), 687-692.

Kuhnhenn, J. Thin target cross sections for proton-induced production of radionuclides from lead and bismuth over the proton energy range from 9 to $71 \mathrm{MeV}$, Thesis of the Universitaet Koeln, 2001, Germany.

Michel, R., Brinkmann, G., Weigel, H., Herr, W. Proton-induced reactions on titanium with energies between 13 and $45 \mathrm{MeV}$. Journal of Inorganic and Nuclear Chemistry, 1978, Volume 40, Issue 11, Pages 1845-1851.

Michel, R., and Brinkmann, G. On the depth-dependent production of radionuclides $(44 \leq \mathrm{A} \leq 59)$ by solar protons in extraterrestrial matter, Journal of Radioanalytical Chemistry, 1980, Volume 59, Issue 2, pp 467-510.

Michel, R., Stueck, R. and Peiffer, F. Proton-Induced Reaction on Ti, V,Mn,Fe,Co and Ni, Journal of Nuclear Physics, Section A, 1985, Vol.441, p.617.

Michel, R.,Bodemann, R., Busemann, H., Daunke, H., Gloris, M., Lange, H.J., Klug, B., Krins, A., Leya, I., Lpke, M., Neumann, S., Reinhardt, H., Schnatz-Bttgen, M., Herpers, U., Schiekel, Th., Sudbrock, F., Holmqvist, B., Cond, H., Malmborg, P., Suter, M., Dittrich-Hannen, B., Kubik, P.W., Synal, H.A. and Filges, D. Cross sections for the production of residual nuclides by low- and medium-energy protons from the target elements $\mathrm{C}, \mathrm{N}, \mathrm{O}, \mathrm{Mg}, \mathrm{Al}$, $\mathrm{Si}, \mathrm{Ca}, \mathrm{Ti}, \mathrm{V}, \mathrm{Mn}, \mathrm{Fe}, \mathrm{Co}, \mathrm{Ni}, \mathrm{Cu}, \mathrm{Sr}, \mathrm{Y}, \mathrm{Zr}, \mathrm{Nb}, \mathrm{Ba}$ and $\mathrm{Au}$, Nuclear Instruments and Methods in Physics Research Section B: Beam Interactions with Materials and Atoms, 1997, Volume 129, Issue 2, Pages 153-193.

Mills, S.J., Steyn, G.F. and Nortier, F.M. Experimental and theoretical excitation functions of radionuclides produced in proton bombardment of copper up to $200 \mathrm{MeV}$, International Journal of Radiation Applications and Instrumentation. Part A. Applied Radiation and Isotopes, 1992, Volume 43, Issue 8, Pages 1019-1030.

Müller, C., Bunka M., Haller S., Kster U., Groehn V., Bernhardt P., Van der Meulen N., Trler A., Schibli R. Promising Prospects for 44Sc-/47ScBased Theragnostics: Application of 47Sc for Radionuclide Tumor Therapy in Mice, J Nucl Med, 2014, vol. 55 n $^{\circ}$ 10, 1658-1664.

Neumann, S. Activation experiments with medium-energy neutrons and the production of cosmogenic nuclides in extraterrestrial matter. Thesis Univ. Hannover (previously Tech.Univ.Hannover), 1999. 
Nichols, A.L. and Capote, R. Nuclear Data for Charged-particle Monitor Reactions and Medical Isotope Productionn Summary Report of the First Research Coordination Meeting, 2013, International Atomic Energy Agency, Vienna, Austria.

Okazawa H., Fujibayashi, Y., Yonekura, Y., Tamaki, N., Nishizawa, S., Magata, Y., Ishizu, K., Tsuchida, T., Sadato, N., Konishi, J., Yokoyama, A., Iwata, R., and Ido, T. Clinical application of $62 \mathrm{Zn} / 62 \mathrm{Cu}$ positron generator: Perfusion and plasma pool images in normal subjects, Annals of Nuclear Medicine, 1995, Volume 9, Issue 2, pp 81-87.

QCALC. Data produced by the code QCALC, written by T.W. Burrows, National Nuclear Data Center, Brookhaven National Laboratory, and based on the Audi-Wapstra Atomic Mass Tables, G. Audi and A.H. Wapstra, The 1995 Update to the Atomic Mass Evaluation., 1995, Nucl. Phys. A 595, 409.

Ravi Shankar, A., Karthiselva, N.S., Kamachi Mudali, U. Thermal oxidation of titanium to improve corrosion resistance in boiling nitric acid medium. Surface and Coatings Technology, 2013, 235, 45-53.

Shahid, M., Kim, K., Naik, H., Zaman, M., Yanga, S-C., Kim G. Measurement of excitation functions in proton induced reactions on natural copper from their threshold to $43 \mathrm{MeV}$. Nuclear Instruments and Methods in Physics Research Section B: Beam Interactions with Materials and Atoms, 2015, Volume 342, Pages 305313.

Siiskonen, T., Huikari, J., Haavisto, T., Bergman, J., Heselius, S.J., Lill, J.O., Lnnroth, T. and Perjrvi, K. Excitation functions of proton-induced reactions in natCu in the energy range 7-17 MeV, Applied Radiation and Isotopes, 2009, Volume 67, Issue 11, Pages 2037-2039.

Sonck, M., Hermanne, A, Szelecsényi, F., Takács, S., Tárkányi, F. 1998. Study of the natNi(p,x)57Ni process up to $44 \mathrm{MeV}$ for monitor purposes. Applied Radiation and Isotopes, Volume 49, Pages 1533.

Szelecsényi, F., Tárkányi, F., Takács, S., Hermanne, A., Sonck, M., Shubin, Yu, Mustafa, M.G and Youxiang, Z. Excitation function for the nuclear process: Evaluation and new measurements for practical applications, Nuclear Instruments and Methods in Physics Research Section B: Beam Interactions with Materials and Atoms, 2001, Volume 174, Issues 1-2, Pages 47-64

Takács, S., Tárkányi, F., Sonck, M. and Hermanne, A. New cross-sections and intercomparison of proton monitor reactions on $\mathrm{Ti}, \mathrm{Ni}$ and $\mathrm{Cu}$, Nuclear Instruments and Methods in Physics Research Section B: Beam Interactions with Materials and Atoms, 2002, Volume 188, Issues 1-4, Pages 106-111. 
Tárkányi, F., Szelecsenyi, F. and Kopecky, P. Cross section data for proton, He-3 and alpha-particle induced reactions on nat-Ni, nat-Cu and nat-Ti for monitoring beam performance. Conf. on Nucl. Data for Sci. and Technol., Juelich, 1991, p.529.

Tárkányi, F., Takács, S., Gul, K., Hermanne, A., Mustafa, M.G., Nortier, M., Oblozinsky, P., Qaim, S.M., Scholten, B., Shubin, Yu.N., Youxiang, Z. Beam monitor reactions, in Charged Particle Cross Section Database for Medical Radioisotope Production: Diagnostic Radioisotopes and Monitor Reactions; IAEA-TECDOC-1211, 2001, pages 49-152, IAEA, Vienna. Database available on https://www-nds.iaea.org/medportal/, update may 2013.

Titarenko, Yu.E., Batyaev, V.F., Titarenko, A.Yu., Butko, M.A., Pavlov, K.V., Florya, S.N., Tikhonov, R.S., Zhivun, V.M., Ignatyuk, A.V., Mashnik, S.G., Leray, S., Boudard, A., Cugnon, J., Mancusi, D., Yariv, Y., Nishihara, K., Matsuda, N., Kumawat, H., Mank, G. and Gudowski W. Measurement and simulation of the cross sections for nuclide production in Nb-93 and $\mathrm{Ni}$ nat targets irradiated with 0.04- to 2.6-GeV protons, Yadernaya Fizika, 2011, Vol.74, p.561

Tárkányi, F.T., Nichols, A.L., Be, M-M., Carlson, B.V., Hussain, M., Ignatyuk, A.V., Kim, G., Kondev, F.G., Lebeda, O., Luca, A., Nagai, T., Naik, H., Nortier, M., and Spahn, I., 2012-2016. CRP on Nuclear Data for Charged-particle Monitor Reactions and Medical Isotope Production.

Topping, G.J., Schaffer, P., Hoehr, C., Ruth, T.J. and Sossi, V. Manganese52 positron emission tomography tracer characterization and initial results in phantoms and in vivo, Med Phys., 2013, 40 (4), 042502 DOI: 10.1118/1.4793756.

Uddin, M.S., Hagiwara, M., Tárkányi, F., Ditroi, F. and Baba, M. Experimental studies on the proton-induced activation reactions of molybdenum in the energy range 22-67 MeV, Applied Radiation and Isotopes, 2004, Volume 60, Issue 6, June 2004, Pages 911-920.

Uddin, M.S., Chakraborty, A.K., Spellerberg, S., Shariff, M.A., Das, S., Rashid, M.A., Ingo Spahn, I., and Qaim, S.M., 2016. Experimental determination of proton induced reaction cross sections on natNi near threshold energy. Radiochimica Acta 104, 5, DOI: 10.1515/ract-2015-2527.

Williams, I.R. and Fulmer, C.B. Excitation Functions for Radioactive Isotopes Produced by Protons below $60 \mathrm{MeV}$ on $\mathrm{Al}, \mathrm{Fe}$, and $\mathrm{Cu}$, Phys. Rev., 1967, 162, 105.

Williams, H.A., Robinson, S., Julyan, P., Zweit, J. and Hastings, D. A comparison of PET imaging characteristics of various copper radioisotopes, 
Eur J Nucl Med Mol Imaging., 2005, 32(12):1473-80.

Yashima, H., Uwamino, Y., Sugita, H., Nakamura, T., Ito, S., and Fukumura, A. Projectile dependence of radioactive spallation products induced in copper by high-energy heavy ions, Phys. Rev. C, 2002, 66, 044607.

Zarie, K., Al-Hammad, N. and Azzam, A. Experimental study of excitation functions of some proton induced reactions on natTi for beam monitoring purposes, Radiochimica Acta., 2006, Volume 94, Issue 12, Pages 795-799.

Ziegler, J.F., Ziegler, M.D. and Biersack, J.P. SRIM The stopping and range of ions in matter, Nucl. Instrum. Methods Phys. Res., Sect. B, 2010, $268,1818-1823$. 
Table 2: physical characteristics of the radionuclides produced in titanium (Kinsey et al., 1996, Ekström and Firestone, 2004) and reaction thresholds (QCALC, 1995).

\begin{tabular}{|c|c|c|c|c|c|}
\hline Radioisotope & $\mathrm{T}_{1 / 2}$ & $\begin{array}{c}\mathrm{E}_{\gamma} \\
(\mathrm{keV})\end{array}$ & $\begin{array}{l}\mathrm{I}_{\gamma} \\
(\%)\end{array}$ & Contributing reactions & $\begin{array}{c}\text { Threshold } \\
(\mathrm{MeV})\end{array}$ \\
\hline \multirow[t]{14}{*}{ Sc-43 } & \multirow[t]{14}{*}{$3.891(12) \mathrm{h}$} & \multirow[t]{14}{*}{372.9} & \multirow[t]{14}{*}{23} & Ti-46(p, $\alpha)$ & 3.14 \\
\hline & & & & $\mathrm{Ti}-46(\mathrm{p}, \mathrm{n}+\mathrm{He}-3)$ & 24.17 \\
\hline & & & & Ti-46(p,2n+2p) & 32.06 \\
\hline & & & & $\mathrm{Ti}-47(\mathrm{p}, \mathrm{n}+\alpha)$ & 12.21 \\
\hline & & & & $\mathrm{Ti}-47(\mathrm{p}, 2 \mathrm{n}+\mathrm{He}-3)$ & 33.23 \\
\hline & & & & Ti-47(p,3n+2p) & 41.11 \\
\hline & & & & $\mathrm{Ti}-48(\mathrm{p}, 2 \mathrm{n}+\alpha)$ & 24.08 \\
\hline & & & & Ti-48(p,3n+He-3) & 45.09 \\
\hline & & & & Ti-48(p,4n+2p) & 52.97 \\
\hline & & & & $\operatorname{Ti}-49(\mathrm{p}, 3 \mathrm{n}+\alpha)$ & 32.38 \\
\hline & & & & $\mathrm{Ti}-49(\mathrm{p}, 4 \mathrm{n}+\mathrm{He}-3)$ & 53.38 \\
\hline & & & & $\mathrm{Ti}-49(\mathrm{p}, 5 \mathrm{n}+2 \mathrm{p})$ & 61.26 \\
\hline & & & & $\mathrm{Ti}-50(\mathrm{p}, 4 \mathrm{n}+\alpha)$ & 43.52 \\
\hline & & & & Ti-50(p,5n+He-3) & 64.52 \\
\hline \multirow[t]{10}{*}{$\mathrm{Sc}-44 \mathrm{~m}$} & \multirow[t]{10}{*}{$58.6(1) \mathrm{h}$} & \multirow[t]{10}{*}{271.13} & \multirow[t]{10}{*}{$86.7(3)$} & Ti-46(p,He-3) & 14.26 \\
\hline & & & & $\mathrm{Ti}-46(\mathrm{p}, 2 \mathrm{p}+\mathrm{n})$ & 22.15 \\
\hline & & & & $\operatorname{Ti}-47(\mathrm{p}, \alpha)$ & 2.30 \\
\hline & & & & $\operatorname{Ti}-47(p, 2 p+2 n)$ & 31.21 \\
\hline & & & & $\operatorname{Ti}-48(\mathrm{p}, \alpha+\mathrm{n})$ & 14.17 \\
\hline & & & & $\operatorname{Ti}-48(p, 2 p+3 n)$ & 43.06 \\
\hline & & & & $\operatorname{Ti}-49(\mathrm{p}, \alpha+2 \mathrm{n})$ & 22.48 \\
\hline & & & & $\operatorname{Ti}-49(\mathrm{p}, 2 \mathrm{p}+4 \mathrm{n})$ & 51.36 \\
\hline & & & & $\operatorname{Ti}-50(\mathrm{p}, \alpha+3 \mathrm{n})$ & 32.28 \\
\hline & & & & $\operatorname{Ti}-50(p, 2 p+5 n)$ & 61.26 \\
\hline \multirow[t]{7}{*}{$\mathrm{Sc}-46$} & \multirow[t]{7}{*}{$83.79(4) \mathrm{d}$} & 889.277 & $99.984(1)$ & Ti-47(p,2p) & 10.69 \\
\hline & & \multirow[t]{6}{*}{1120.545} & \multirow[t]{6}{*}{$99.987(1)$} & Ti-48(p,He-3) & 14.68 \\
\hline & & & & $\mathrm{Ti}-48(\mathrm{p}, 2 \mathrm{p}+\mathrm{n})$ & 22.56 \\
\hline & & & & $\operatorname{Ti}-49(\mathrm{p}, \alpha)$ & 1.98 \\
\hline & & & & $\operatorname{Ti}-49(\mathrm{p}, 2 \mathrm{p}+2 \mathrm{n})$ & 30.86 \\
\hline & & & & Ti-50(p,,$\alpha+\mathrm{n})$ & 13.14 \\
\hline & & & & $\operatorname{Ti}-50(p, 2 p+3 n)$ & 42.00 \\
\hline
\end{tabular}


Table 2 (continued): physical characteristics of the radionuclides produced in titanium (Kinsey et al., 1996, Ekström and Firestone, 2004) and reaction thresholds (QCALC, 1995).

\begin{tabular}{|c|c|c|c|c|c|}
\hline Radioisotope & $\mathrm{T}_{1 / 2}$ & $\begin{array}{c}\mathrm{E}_{\gamma} \\
(\mathrm{keV})\end{array}$ & $\begin{array}{l}\mathrm{I}_{\gamma} \\
(\%)\end{array}$ & Contributing reactions & $\begin{array}{c}\text { Threshold } \\
(\mathrm{MeV})\end{array}$ \\
\hline \multirow[t]{5}{*}{ Sc-47 } & $3.3492(6) \mathrm{d}$ & 159.377 & $68.3(4)$ & Ti-48(p,2p) & 11.69 \\
\hline & & & & Ti-49(p,He-3) & 12.11 \\
\hline & & & & $\operatorname{Ti}-49(\mathrm{p}, 2 \mathrm{p}+\mathrm{n})$ & 19.99 \\
\hline & & & & Ti-50(p, $\alpha)$ & 2.28 \\
\hline & & & & $\mathrm{Ti}-50(\mathrm{p}, 2 \mathrm{p}+2 \mathrm{n})$ & 31.14 \\
\hline \multirow[t]{3}{*}{ Sc- 48} & $43.67(9) \mathrm{h}$ & 175.361 & $7.48(9)$ & Ti-49(p,2p) & 11.58 \\
\hline & & 1037.599 & $97.6(5)$ & Ti-50(p,He-3) & 14.86 \\
\hline & & & & $\mathrm{Ti}-50(\mathrm{p}, 2 \mathrm{p}+\mathrm{n})$ & 22.73 \\
\hline \multirow[t]{3}{*}{$\mathrm{V}-48$} & $15.9735(25) \mathrm{d}$ & 944.104 & $7.76(9)$ & Ti-48(p,n) & 4.90 \\
\hline & & 983.517 & $99.98(20)$ & $\mathrm{Ti}-49(\mathrm{p}, 2 \mathrm{n})$ & 13.21 \\
\hline & & 1312.096 & $97.5(8)$ & Ti-50(p,3n) & 23.97 \\
\hline \multirow[t]{8}{*}{$\mathrm{K}-42$} & $12.360(3) \mathrm{h}$ & 1524.7 & 18 & $\mathrm{Ti}-46(\mathrm{p}, 2 \mathrm{p}+\mathrm{He}-3)$ & 32.01 \\
\hline & & & & Ti-46(p,4p+n) & 39.90 \\
\hline & & & & $\operatorname{Ti}-47(\mathrm{p}, 2 \mathrm{p}+\alpha)$ & 20.05 \\
\hline & & & & $\mathrm{Ti}-47(\mathrm{p}, 4 \mathrm{p}+2 \mathrm{n})$ & 48.95 \\
\hline & & & & $\operatorname{Ti}-48(\mathrm{p}, 2 \mathrm{p}+\alpha+\mathrm{n})$ & 31.91 \\
\hline & & & & Ti-48(p,4p+3n) & 60.80 \\
\hline & & & & $\operatorname{Ti}-49(\mathrm{p}, 2 \mathrm{p}+\alpha+2 \mathrm{n})$ & 40.21 \\
\hline & & & & Ti-49(p,4p+4n) & 69.09 \\
\hline \multirow[t]{7}{*}{$\mathrm{K}-43$} & $22.3(1) \mathrm{h}$ & 372.76 & 87 & Ti-46(p,4p) & 30.06 \\
\hline & & 396.86 & $11.85(8)$ & $\mathrm{Ti}-47(\mathrm{p}, 2 \mathrm{p}+\mathrm{He}-3)$ & 31.24 \\
\hline & & 593.39 & $11.26(8)$ & Ti-47(p,4p+n) & 39.12 \\
\hline & & 617.49 & $76.2(6)$ & $\operatorname{Ti}-48(\mathrm{p}, 2 \mathrm{p}+\alpha)$ & 22.08 \\
\hline & & & & $\mathrm{Ti}-48(\mathrm{p}, 4 \mathrm{p}+2 \mathrm{n})$ & 50.97 \\
\hline & & & & $\mathrm{Ti}-49(\mathrm{p}, 2 \mathrm{p}+\alpha+\mathrm{n})$ & 30.39 \\
\hline & & & & $\mathrm{Ti}-49(\mathrm{p}, 4 \mathrm{p}+3 \mathrm{n})$ & 59.26 \\
\hline
\end{tabular}


Table 3: experimental cross section values for Ti-nat(p,x)Sc-43,44m,46,47,48, V-48, K42,43 reactions.

\begin{tabular}{|c|c|c|c|c|}
\hline Energy $(\mathrm{MeV})$ & $\sigma \mathrm{Sc}-43(\mathrm{mb})$ & $\sigma \mathrm{Sc}-44 \mathrm{~m}(\mathrm{mb})$ & $\sigma \mathrm{Sc}-46(\mathrm{mb})$ & $\sigma \mathrm{Sc}-47(\mathrm{mb})$ \\
\hline $69.90 \pm 0.56$ & $8.81 \pm 2.76$ & $18.74 \pm 1.29$ & $45.07 \pm 3.14$ & $19.39 \pm 1.31$ \\
\hline $57.44 \pm 1.03$ & $11.85 \pm 4.33$ & $12.43 \pm 1.17$ & $51.21 \pm 4.87$ & $20.35 \pm 1.89$ \\
\hline $45.54 \pm 0.59$ & $11.84 \pm 4.83$ & $10.78 \pm 0.96$ & $63.98 \pm 5.85$ & $19.17 \pm 1.69$ \\
\hline $40.64 \pm 0.84$ & & $12.88 \pm 1.15$ & $60.15 \pm 5.52$ & $20.59 \pm 1.81$ \\
\hline $36.48 \pm 0.91$ & & $15.46 \pm 1.37$ & $43.21 \pm 3.93$ & $22.43 \pm 1.96$ \\
\hline $29.65 \pm 0.59$ & & $15.38 \pm 1.36$ & $14.53 \pm 1.37$ & $24.44 \pm 2.11$ \\
\hline $24.90 \pm 0.80$ & & $8.33 \pm 0.78$ & $10.42 \pm 1.01$ & $15.21 \pm 1.38$ \\
\hline $19.36 \pm 1.09$ & & $1.07 \pm 0.17$ & $5.18 \pm 0.76$ & $4.26 \pm 0.56$ \\
\hline $17.33 \pm 1.16$ & & $1.00 \pm 0.16$ & $3.94 \pm 0.62$ & $1.84 \pm 0.27$ \\
\hline $17.06 \pm 1.26$ & & $0.97 \pm 0.07$ & $3.45 \pm 0.51$ & $1.37 \pm 0.14$ \\
\hline $15.11 \pm 1.34$ & $3.47 \pm 2.08$ & $0.75 \pm 0.09$ & $2.80 \pm 0.40$ & $0.88 \pm 0.10$ \\
\hline $13.55 \pm 1.48$ & & $0.53 \pm 0.22$ & & $0.72 \pm 0.16$ \\
\hline \multicolumn{5}{|l|}{$10.01 \pm 1.90$} \\
\hline Energy $(\mathrm{MeV})$ & $\sigma \mathrm{Sc}-48(\mathrm{mb})$ & $\sigma \mathrm{V}-48(\mathrm{mb})$ & $\sigma \mathrm{K}-42(\mathrm{mb})$ & $\sigma \mathrm{K}-43(\mathrm{mb})$ \\
\hline $69.90 \pm 0.56$ & $1.81 \pm 0.17$ & $10.37 \pm 0.73$ & $5.99 \pm 0.75$ & $1.20 \pm 0.12$ \\
\hline $57.44 \pm 1.03$ & $1.83 \pm 0.22$ & $14.48 \pm 1.48$ & $4.19 \pm 0.65$ & $1.33 \pm 0.15$ \\
\hline $45.54 \pm 0.59$ & $1.53 \pm 0.15$ & $19.24 \pm 1.84$ & $0.62 \pm 0.16$ & $0.70 \pm 0.07$ \\
\hline $40.64 \pm 0.84$ & $1.40 \pm 0.14$ & $25.25 \pm 2.37$ & & $0.21 \pm 0.04$ \\
\hline $36.48 \pm 0.91$ & $1.11 \pm 0.12$ & $29.03 \pm 2.65$ & & \\
\hline $29.65 \pm 0.59$ & $0.65 \pm 0.14$ & $36.93 \pm 3.39$ & & \\
\hline $24.90 \pm 0.80$ & $0.34 \pm 0.12$ & $51.26 \pm 4.79$ & & \\
\hline $19.36 \pm 1.09$ & & & & \\
\hline $17.33 \pm 1.16$ & & & & \\
\hline $17.06 \pm 1.26$ & & & & \\
\hline $15.11 \pm 1.34$ & & & & \\
\hline $13.55 \pm 1.48$ & & & & \\
\hline $10.01 \pm 1.90$ & & & & \\
\hline
\end{tabular}


Table 4: physical characteristics of the radionuclides produced in nickel (Kinsey et al., 1996, Ekström and Firestone, 2004) and reaction thresholds (QCALC, 1995).

\begin{tabular}{|c|c|c|c|c|c|}
\hline Radioisotope & $\mathrm{T}_{1 / 2}$ & $\begin{array}{c}\mathrm{E}_{\gamma} \\
(\mathrm{keV})\end{array}$ & $\begin{array}{l}\mathrm{I}_{\gamma} \\
(\%)\end{array}$ & Contributing reactions & $\begin{array}{c}\text { Threshold } \\
(\mathrm{MeV})\end{array}$ \\
\hline \multirow[t]{6}{*}{$\mathrm{Ni}-56$} & $6.077(12) \mathrm{d}$ & 158.38 & $98.8(10)$ & $\mathrm{Ni}-58(p, p+2 n)$ & 22.85 \\
\hline & & 269.5 & $36.5(8)$ & $\mathrm{Ni}-60(\mathrm{p}, \mathrm{p}+4 \mathrm{n})$ & 43.57 \\
\hline & & 480.44 & $36.5(8)$ & $\mathrm{Ni}-61(p, p+5 n)$ & 51.51 \\
\hline & & 749.95 & $49.5(12)$ & $\mathrm{Ni}-62(p, p+6 n)$ & 62.26 \\
\hline & & 811.85 & $86.0(9)$ & & \\
\hline & & 1561.8 & $14.0(6)$ & & \\
\hline \multirow[t]{5}{*}{$\mathrm{Ni}-57$} & $35.60(6) \mathrm{h}$ & 127.164 & $16.7(3)$ & $\mathrm{Ni}-58(\mathrm{p}, \mathrm{p}+\mathrm{n})$ & 12.43 \\
\hline & & 1377.64 & $81.7(16)$ & $\mathrm{Ni}-60(p, p+3 n)$ & 33.15 \\
\hline & & 1757.55 & $5.75(16)$ & $\mathrm{Ni}-61(p, p+4 n)$ & 41.09 \\
\hline & & 1919.52 & $12.26(25)$ & $\mathrm{Ni}-62(p, p+5 n)$ & 51.85 \\
\hline & & & & $\mathrm{Ni}-64(\mathrm{p}, \mathrm{p}+7 \mathrm{n})$ & 68.58 \\
\hline \multirow[t]{8}{*}{ Co-55 } & $17.53(3) \mathrm{h}$ & 91.9 & $1.16(7)$ & $\mathrm{Ni}-58(\mathrm{p}, \alpha)$ & 1.36 \\
\hline & & 411.9 & $1.07(7)$ & $\mathrm{Ni}-58(\mathrm{p}, 2 \mathrm{p}+2 \mathrm{n})$ & 30.15 \\
\hline & & 477.2 & $20.2(14)$ & $\mathrm{Ni}-60(\mathrm{p}, \alpha+2 \mathrm{n})$ & 22.09 \\
\hline & & 803.4 & $1.87(13)$ & $\mathrm{Ni}-60(p, 2 p+4 n)$ & 50.86 \\
\hline & & 931.3 & 75 & $\mathrm{Ni}-61(\mathrm{p}, \alpha+3 \mathrm{n})$ & 30.03 \\
\hline & & 1316.4 & $7.09(10)$ & $\mathrm{Ni}-61(p, 2 p+5 n)$ & 65.19 \\
\hline & & 1369.7 & $2.92(22)$ & $\mathrm{Ni}-62(\mathrm{p}, \alpha+4 \mathrm{n})$ & 40.79 \\
\hline & & 1408.4 & $16.88(8)$ & $\mathrm{Ni}-64(\mathrm{p}, \alpha+6 \mathrm{n})$ & 57.53 \\
\hline \multirow[t]{13}{*}{ Co-56 } & $77.27(3) \mathrm{d}$ & 846.771 & 100 & $\mathrm{Ni}-58(\mathrm{p}, \mathrm{d}+\mathrm{p})$ & 17.63 \\
\hline & & 1037.84 & $13.99(10)$ & $\mathrm{Ni}-58(\mathrm{p}, 2 \mathrm{p}+\mathrm{n})$ & 19.89 \\
\hline & & 1238.282 & $67.6(4)$ & $\mathrm{Ni}-60(\mathrm{p}, \alpha+\mathrm{n})$ & 11.84 \\
\hline & & 1360.215 & $4.33(4)$ & $\mathrm{Ni}-60(\mathrm{p}, \mathrm{He}-3+2 \mathrm{n})$ & 32.76 \\
\hline & & 1771.351 & $15.69(15)$ & Ni-60(p,2p+3n) & 40.61 \\
\hline & & & & Ni-61(p, $\alpha+2 \mathrm{n})$ & 19.78 \\
\hline & & & & $\mathrm{Ni}-61(p, \mathrm{He}-3+3 \mathrm{n})$ & 40.70 \\
\hline & & & & $\mathrm{Ni}-61(\mathrm{p}, 2 \mathrm{p}+4 \mathrm{n})$ & 48.55 \\
\hline & & & & $\mathrm{Ni}-62(\mathrm{p}, \alpha+3 \mathrm{n})$ & 30.54 \\
\hline & & & & $\mathrm{Ni}-62(\mathrm{p}, \mathrm{He}-3+4 \mathrm{n})$ & 51.46 \\
\hline & & & & $\mathrm{Ni}-62(\mathrm{p}, 2 \mathrm{p}+5 \mathrm{n})$ & 59.30 \\
\hline & & & & $\mathrm{Ni}-64(\mathrm{p}, \alpha+5 \mathrm{n})$ & 47.28 \\
\hline & & & & + Ni-56 decay & \\
\hline
\end{tabular}


Table 4 (continued): physical characteristics of the radionuclides produced in nickel (Kinsey et al., 1996, Ekström and Firestone, 2004) and reaction thresholds (QCALC, 1995).

\begin{tabular}{|c|c|c|c|c|c|}
\hline Radioisotope & $\mathrm{T}_{1 / 2}$ & $\begin{array}{c}\mathrm{E}_{\gamma} \\
(\mathrm{keV}) \\
\end{array}$ & $\begin{array}{c}\mathrm{I}_{\gamma} \\
(\%) \\
\end{array}$ & Contributing reactions & $\begin{array}{c}\text { Threshold } \\
(\mathrm{MeV})\end{array}$ \\
\hline \multirow[t]{14}{*}{ Co-57 } & \multirow[t]{14}{*}{$271.79(9) \mathrm{d}$} & 122.0614 & $85.60(17)$ & Ni-58(p,2p) & 8.31 \\
\hline & & \multirow[t]{13}{*}{136.4743} & \multirow[t]{13}{*}{$10.68(8)$} & $\mathrm{Ni}-60(\mathrm{p}, \alpha)$ & 0.27 \\
\hline & & & & $\mathrm{Ni}-60(\mathrm{p}, \mathrm{He}-3+\mathrm{n})$ & 21.19 \\
\hline & & & & $\mathrm{Ni}-60(p, 2 p+2 n)$ & 29.04 \\
\hline & & & & $\mathrm{Ni}-61(\mathrm{p}, \alpha+\mathrm{n})$ & 8.22 \\
\hline & & & & $\mathrm{Ni}-61(\mathrm{p}, \mathrm{He}-3+2 \mathrm{n})$ & 29.14 \\
\hline & & & & Ni-61(p,2p+3n) & 36.98 \\
\hline & & & & $\mathrm{Ni}-62(\mathrm{p}, \alpha+2 \mathrm{n})$ & 18.98 \\
\hline & & & & Ni-62(p,He-3+3n) & 39.90 \\
\hline & & & & Ni-62(p,2p+4n) & 47.74 \\
\hline & & & & $\mathrm{Ni}-64(\mathrm{p}, \alpha+4 \mathrm{n})$ & 35.73 \\
\hline & & & & $\mathrm{Ni}-64(\mathrm{p}, \mathrm{He}-3+5 \mathrm{n})$ & 56.63 \\
\hline & & & & $\mathrm{Ni}-64(\mathrm{p}, 2 \mathrm{p}+6 \mathrm{n})$ & 64.47 \\
\hline & & & & $+\mathrm{Ni}-57$ decay & \\
\hline \multirow[t]{11}{*}{ Co-58 } & \multirow[t]{11}{*}{$70.86(7) \mathrm{d}$} & \multirow[t]{11}{*}{810.775} & \multirow[t]{11}{*}{99} & $\mathrm{Ni}-60(\mathrm{p}, \mathrm{d}+\mathrm{p})$ & 18.06 \\
\hline & & & & $\mathrm{Ni}-60(p, 2 p+n)$ & 20.32 \\
\hline & & & & Ni-61(p, $\alpha)$ & 0.00 \\
\hline & & & & Ni-61 $(p, H e-3+n)$ & 20.42 \\
\hline & & & & $\mathrm{Ni}-61(p, 2 p+2 n)$ & 28.27 \\
\hline & & & & $\mathrm{Ni}-62(\mathrm{p}, \alpha+\mathrm{n})$ & 10.27 \\
\hline & & & & $\mathrm{Ni}-62(p, \mathrm{He}-3+2 \mathrm{n})$ & 31.18 \\
\hline & & & & Ni-62(p,2p+3n) & 39.03 \\
\hline & & & & Ni-64(p, $\alpha+2 \mathrm{n})$ & 18.98 \\
\hline & & & & $\mathrm{Ni}-64(\mathrm{p}, \mathrm{He}-3+2 \mathrm{n})$ & 39.90 \\
\hline & & & & $\mathrm{Ni}-64(\mathrm{p}, 2 \mathrm{p}+3 \mathrm{n})$ & 47.74 \\
\hline \multirow[t]{8}{*}{ Mn-52 } & \multirow{8}{*}{$5.591(3) \mathrm{d}$} & 744.233 & $90.0(8)$ & $\mathrm{Ni}-58(\mathrm{p}, \alpha+2 \mathrm{p}+\mathrm{n})$ & 27.78 \\
\hline & & 935.538 & $94.5(9)$ & $\mathrm{Ni}-58(\mathrm{p}, \mathrm{He}-3+2 \mathrm{p}+2 \mathrm{n})$ & 48.72 \\
\hline & & 1246.278 & $4.21(6)$ & $\mathrm{Ni}-60(\mathrm{p}, 2 \alpha+\mathrm{n})$ & 19.72 \\
\hline & & 1333.649 & $5.07(5)$ & $\mathrm{Ni}-60(\mathrm{p}, \alpha+2 \mathrm{p}+3 \mathrm{n})$ & 48.50 \\
\hline & & 1434.068 & $100.0(5)$ & $\mathrm{Ni}-61(\mathrm{p}, 2 \alpha+2 \mathrm{n})$ & 27.67 \\
\hline & & & & $\mathrm{Ni}-61(\mathrm{p}, \alpha+2 \mathrm{p}+4 \mathrm{n})$ & 56.43 \\
\hline & & & & $\mathrm{Ni}-62(\mathrm{p}, 2 \alpha+3 \mathrm{n})$ & 38.43 \\
\hline & & & & $\mathrm{Ni}-62(\mathrm{p}, \alpha+2 \mathrm{p}+5 \mathrm{n})$ & 67.19 \\
\hline \multirow[t]{8}{*}{ Mn-54 } & \multirow[t]{8}{*}{$312.3(4) \mathrm{d}$} & \multirow[t]{8}{*}{834.848} & \multirow[t]{8}{*}{$99.976(1)$} & $\mathrm{Ni}-58(\mathrm{p}, 4 \mathrm{p}+\mathrm{n})$ & 35.21 \\
\hline & & & & $\mathrm{Ni}-60(\mathrm{p}, \alpha+2 \mathrm{p}+\mathrm{n})$ & 27.15 \\
\hline & & & & $\mathrm{Ni}-60(p, \mathrm{He}-3+2 \mathrm{p}+2 \mathrm{n})$ & 48.07 \\
\hline & & & & $\mathrm{Ni}-60(p, 4 p+3 n)$ & 55.92 \\
\hline & & & & $\mathrm{Ni}-61(\mathrm{p}, 2 \alpha)$ & 6.33 \\
\hline & & & & $\mathrm{Ni}-61(p, 4 p+4 n)$ & 63.86 \\
\hline & & & & $\mathrm{Ni}-62(\mathrm{p}, 2 \alpha+\mathrm{n})$ & 17.10 \\
\hline & & & & $\mathrm{Ni}-64(p, 2 \alpha+3 \mathrm{n})$ & 33.84 \\
\hline
\end{tabular}


Table 5: experimental cross section values for Ni-nat(p,x)Co-55,56,57,58, Ni-56,57, Mn52,54 reactions.

\begin{tabular}{ccccc}
\hline Energy $(\mathrm{MeV})$ & $\sigma$ Co-55 $(\mathrm{mb})$ & $\sigma$ Co-56 $(\mathrm{mb})$ & $\sigma$ Co-57 $(\mathrm{mb})$ & $\sigma$ Co-58 $(\mathrm{mb})$ \\
\hline $69.81 \pm 0.57$ & $30.73 \pm 2.11$ & $102.63 \pm 7.56$ & $156.77 \pm 10.42$ & $32.95 \pm 2.68$ \\
$57.34 \pm 1.07$ & $39.72 \pm 3.71$ & $119.03 \pm 11.32$ & $199.61 \pm 18.18$ & $41.85 \pm 4.09$ \\
$45.66 \pm 0.58$ & $20.64 \pm 1.85$ & $178.99 \pm 16.14$ & $198.22 \pm 17.17$ & $57.04 \pm 5.32$ \\
$40.78 \pm 0.80$ & $8.28 \pm 0.76$ & $222.65 \pm 19.93$ & $203.67 \pm 17.60$ & $68.46 \pm 6.33$ \\
$36.63 \pm 0.92$ & $4.18 \pm 0.40$ & $208.11 \pm 18.74$ & $232.48 \pm 20.11$ & $62.97 \pm 5.84$ \\
$29.85 \pm 0.58$ & $3.43 \pm 0.38$ & $83.22 \pm 7.36$ & $428.46 \pm 36.16$ & $22.30 \pm 2.05$ \\
$25.13 \pm 0.85$ & $6.45 \pm 0.65$ & $15.36 \pm 1.49$ & $549.91 \pm 48.68$ & $6.15 \pm 0.64$ \\
$19.63 \pm 1.08$ & $21.01 \pm 2.75$ & $0.96 \pm 0.17$ & $436.30 \pm 55.85$ & $2.40 \pm 0.35$ \\
$17.62 \pm 1.17$ & $24.08 \pm 3.28$ & $0.43 \pm 0.10$ & $313.11 \pm 41.96$ & $1.70 \pm 0.26$ \\
$17.33 \pm 1.20$ & $24.75 \pm 1.79$ & & $268.99 \pm 18.39$ & $2.63 \pm 0.21$ \\
$15.43 \pm 1.35$ & $21.79 \pm 2.50$ & & $132.96 \pm 15.68$ & \\
$13.86 \pm 1.49$ & $15.55 \pm 1.13$ & & $24.42 \pm 1.72$ & $2.20 \pm 0.23$ \\
$10.39 \pm 1.86$ & $3.54 \pm 0.33$ & & $5.45 \pm 0.59$ & $2.00 \pm 0.25$ \\
\hline Energy (MeV) & $\sigma \mathrm{Ni}-56(\mathrm{mb})$ & $\sigma \mathrm{Ni}-57(\mathrm{mb})$ & $\sigma \mathrm{Mn}-52(\mathrm{mb})$ & $\sigma \mathrm{Mn}-54(\mathrm{mb})$ \\
\hline $69.81 \pm 0.57$ & $8.18 \pm 0.58$ & $64.41 \pm 4.62$ & $17.59 \pm 1.32$ & $23.78 \pm 2.99$ \\
$57.34 \pm 1.07$ & $9.29 \pm 0.88$ & $74.85 \pm 7.19$ & $23.34 \pm 2.17$ & $13.78 \pm 1.77$ \\
$45.66 \pm 0.58$ & $11.85 \pm 1.05$ & & $2.99 \pm 0.27$ & $2.05 \pm 0.89$ \\
$40.78 \pm 0.80$ & $12.75 \pm 1.13$ & & $0.42 \pm 0.05$ & $1.04 \pm 0.55$ \\
$36.63 \pm 0.92$ & $10.01 \pm 0.89$ & & & \\
$29.85 \pm 0.58$ & $3.80 \pm 0.35$ & & & $1.22 \pm 0.56$ \\
$25.13 \pm 0.85$ & $1.10 \pm 0.13$ & & & \\
$19.63 \pm 1.08$ & $0.26 \pm 0.07$ & $95.08 \pm 12.52$ & & $0.83 \pm 0.41$ \\
$17.62 \pm 1.17$ & & $45.63 \pm 6.27$ & & \\
$17.33 \pm 1.20$ & & $28.07 \pm 2.12$ & & \\
$15.43 \pm 1.35$ & & $8.07 \pm 0.96$ & & \\
$13.86 \pm 1.49$ & & $0.13 \pm 0.04$ & & \\
$10.39 \pm 1.86$ & & & & \\
\hline
\end{tabular}


Table 6: physical characteristics of the radionuclides produced in copper (Kinsey et al., 1996, Ekström and Firestone, 2004) and reaction thresholds (QCALC, 1995).

\begin{tabular}{|c|c|c|c|c|c|}
\hline Radioisotope & $\mathrm{T}_{1 / 2}$ & $\begin{array}{c}\mathrm{E}_{\gamma} \\
(\mathrm{keV})\end{array}$ & $\begin{array}{l}\mathrm{I}_{\gamma} \\
(\%)\end{array}$ & Contributing reactions & $\begin{array}{c}\text { Threshold } \\
(\mathrm{MeV})\end{array}$ \\
\hline \multirow[t]{6}{*}{$\mathrm{Zn}-62$} & \multirow[t]{6}{*}{$9.1786(13) \mathrm{h}$} & 243.39 & $2.52(13)$ & $\mathrm{Cu}-63(\mathrm{p}, 2 \mathrm{n})$ & 13.48 \\
\hline & & 246.96 & $1.9(1)$ & \multirow[t]{5}{*}{$\mathrm{Cu}-65(\mathrm{p}, 4 \mathrm{n})$} & \multirow[t]{5}{*}{31.57} \\
\hline & & 260.43 & $1.35(8)$ & & \\
\hline & & 394.03 & $2.236(10)$ & & \\
\hline & & 548.35 & $15.3(8)$ & & \\
\hline & & 596.56 & 26 & & \\
\hline $\mathrm{Zn}-65$ & $244.26(26) \mathrm{d}$ & 1115.546 & $50.60(24)$ & $\mathrm{Cu}-65(\mathrm{p}, \mathrm{n})$ & 2.17 \\
\hline \multirow[t]{5}{*}{$\mathrm{Ni}-57$} & \multirow[t]{5}{*}{$35.60(6) \mathrm{h}$} & 127.164 & $16.7(3)$ & $\mathrm{Cu}-63(\mathrm{p}, \alpha+3 \mathrm{n})$ & 29.31 \\
\hline & & 1377.64 & $81.7(16)$ & $\mathrm{Cu}-63(\mathrm{p}, \mathrm{He}-3+4 \mathrm{n})$ & 50.21 \\
\hline & & 1757.55 & $5.75(16)$ & $\mathrm{Cu}-63(\mathrm{p}, 2 \mathrm{p}+5 \mathrm{n})$ & 58.06 \\
\hline & & 1919.52 & $12.26(25)$ & $\mathrm{Cu}-65(\mathrm{p}, \alpha+5 \mathrm{n})$ & 47.40 \\
\hline & & & & $\mathrm{Cu}-65(\mathrm{p}, \mathrm{He}-3+6 \mathrm{n})$ & 68.29 \\
\hline \multirow[t]{5}{*}{ Co-56 } & \multirow[t]{5}{*}{$77.27(3) \mathrm{d}$} & 846.771 & 100 & $\mathrm{Cu}-63(\mathrm{p}, \alpha+\mathrm{p}+3 \mathrm{n})$ & 36.76 \\
\hline & & 1037.84 & $13.99(10)$ & $\mathrm{Cu}-63(\mathrm{p}, 3 \mathrm{p}+5 \mathrm{n})$ & 65.51 \\
\hline & & 1238.282 & $67.6(4)$ & $\mathrm{Cu}-65(\mathrm{p}, \alpha+\mathrm{p}+5 \mathrm{n})$ & 54.84 \\
\hline & & 1360.215 & $4.33(4)$ & & \\
\hline & & 1771.351 & $15.69(15)$ & & \\
\hline \multirow[t]{6}{*}{ Co- 57} & \multirow[t]{6}{*}{$271.79(9) \mathrm{d}$} & 122.0614 & $85.60(17)$ & $\mathrm{Cu}-63(\mathrm{p}, \alpha+\mathrm{p}+2 \mathrm{n})$ & 25.20 \\
\hline & & 136.4743 & $10.68(8)$ & $\mathrm{Cu}-63(\mathrm{p}, \mathrm{He}-3+\mathrm{p}+3 \mathrm{n})$ & 46.11 \\
\hline & & & & $\mathrm{Cu}-63(\mathrm{p}, 3 \mathrm{p}+4 \mathrm{n})$ & 53.95 \\
\hline & & & & $\mathrm{Cu}-65(\mathrm{p}, \alpha+\mathrm{p}+4 \mathrm{n})$ & 47.00 \\
\hline & & & & $\mathrm{Cu}-65(\mathrm{p}, \mathrm{He}-3+\mathrm{p}+5 \mathrm{n})$ & 64.19 \\
\hline & & & & $+\mathrm{Ni}-57$ decay & \\
\hline \multirow[t]{6}{*}{ Co-58 } & \multirow[t]{6}{*}{$70.86(7) \mathrm{d}$} & \multirow[t]{6}{*}{810.775} & \multirow[t]{6}{*}{99} & $\mathrm{Cu}-63(\mathrm{p}, \alpha+\mathrm{p}+\mathrm{n})$ & 16.49 \\
\hline & & & & $\mathrm{Cu}-63(\mathrm{p}, \mathrm{He}-3+\mathrm{p}+2 \mathrm{n})$ & 37.40 \\
\hline & & & & $\mathrm{Cu}-63(\mathrm{p}, 3 \mathrm{p}+3 \mathrm{n})$ & 45.24 \\
\hline & & & & $\mathrm{Cu}-65(\mathrm{p}, \alpha+\mathrm{p}+3 \mathrm{n})$ & 34.58 \\
\hline & & & & $\mathrm{Cu}-65(\mathrm{p}, \mathrm{He}-3+\mathrm{p}+4 \mathrm{n})$ & 55.48 \\
\hline & & & & $\mathrm{Cu}-65(\mathrm{p}, 3 \mathrm{p}+5 \mathrm{n})$ & 63.32 \\
\hline
\end{tabular}


Table 6 (continued): physical characteristics of the radionuclides produced in copper (Kinsey et al., 1996, Ekström and Firestone, 2004) and reaction thresholds (QCALC, 1995).

\begin{tabular}{|c|c|c|c|c|c|}
\hline Radioisotope & $\mathrm{T}_{1 / 2}$ & $\begin{array}{c}\mathrm{E}_{\gamma} \\
(\mathrm{keV})\end{array}$ & $\begin{array}{l}\mathrm{I}_{\gamma} \\
(\%)\end{array}$ & Contributing reactions & $\begin{array}{c}\text { Threshold } \\
(\mathrm{MeV})\end{array}$ \\
\hline \multirow[t]{3}{*}{ Co-60 } & $5.2714(5) \mathrm{y}$ & 1173.237 & $99.9736(7)$ & $\mathrm{Cu}-63(\mathrm{p}, 3 \mathrm{p}+\mathrm{n})$ & 27.00 \\
\hline & & 1332.501 & $99.9856(4)$ & $\mathrm{Cu}-65(\mathrm{p}, \alpha+\mathrm{p}+\mathrm{n})$ & 16.36 \\
\hline & & & & $\mathrm{Cu}-65(\mathrm{p}, 3 \mathrm{p}+3 \mathrm{n})$ & 45.09 \\
\hline \multirow[t]{6}{*}{$\mathrm{Cu}-61$} & $3.333(5) \mathrm{h}$ & 282.956 & $12.2(3)$ & $\mathrm{Cu}-63(\mathrm{p}, \mathrm{p}+2 \mathrm{n})$ & 20.05 \\
\hline & & 373.05 & $2.15(5)$ & $\mathrm{Cu}-65(\mathrm{p}, \mathrm{p}+4 \mathrm{n})$ & 38.15 \\
\hline & & 588.605 & $1.168(21)$ & & \\
\hline & & 656.008 & $10.77(18)$ & & \\
\hline & & 908.631 & $1.102(21)$ & & \\
\hline & & 1185.234 & $3.75(7)$ & & \\
\hline \multirow[t]{2}{*}{$\mathrm{Cu}-64$} & $12.700(2) \mathrm{h}$ & 1345.84 & $0.473(10)$ & $\mathrm{Cu}-65(\mathrm{p}, \mathrm{d})$ & 7.81 \\
\hline & & & & $\mathrm{Cu}-65(\mathrm{p}, \mathrm{p}+\mathrm{n})$ & 10.06 \\
\hline \multirow[t]{4}{*}{ Mn-54 } & $312.3(4) \mathrm{d}$ & 834.848 & $99.976(1)$ & $\mathrm{Cu}-63(\mathrm{p}, 2 \alpha+\mathrm{d})$ & 21.05 \\
\hline & & & & $\mathrm{Cu}-63(\mathrm{p}, 2 \alpha+\mathrm{p}+\mathrm{n})$ & 23.31 \\
\hline & & & & $\mathrm{Cu}-65(\mathrm{p}, 2 \alpha+\mathrm{d}+2 \mathrm{n})$ & 39.14 \\
\hline & & & & $\mathrm{Cu}-65(\mathrm{p}, 2 \alpha+\mathrm{p}+3 \mathrm{n})$ & 41.40 \\
\hline
\end{tabular}


Table 7: experimental cross section values for Cu-nat(p,x)Zn-62,65, Ni-57, Co-56,57,58,60, $\mathrm{Cu}-61,64, \mathrm{Mn}-54$ reactions.

\begin{tabular}{|c|c|c|c|c|}
\hline Energy $(\mathrm{MeV})$ & $\sigma \mathrm{Zn}-62(\mathrm{mb})$ & $\sigma \mathrm{Zn}-65(\mathrm{mb})$ & $\sigma \mathrm{Ni}-57(\mathrm{mb})$ & $\sigma \mathrm{Co}-56(\mathrm{mb})$ \\
\hline $70.08 \pm 0.54$ & $6.59 \pm 0.51$ & $3.28 \pm 0.54$ & $1.19 \pm 0.09$ & \\
\hline $69.99 \pm 0.55$ & $6.71 \pm 0.53$ & $2.89 \pm 0.80$ & $1.15 \pm 0.12$ & \\
\hline $69.73 \pm 0.59$ & $6.46 \pm 0.43$ & $3.17 \pm 0.48$ & $1.24 \pm 0.08$ & \\
\hline $63.86 \pm 0.86$ & $7.11 \pm 0.38$ & $3.28 \pm 0.42$ & $1.57 \pm 0.11$ & \\
\hline $63.49 \pm 0.92$ & $7.34 \pm 0.39$ & $3.62 \pm 0.48$ & $1.83 \pm 0.12$ & \\
\hline $57.55 \pm 1.07$ & & $4.17 \pm 0.90$ & $2.17 \pm 0.24$ & $3.32 \pm 0.36$ \\
\hline $57.12 \pm 1.09$ & & $4.46 \pm 0.62$ & $2.11 \pm 0.21$ & $2.80 \pm 0.20$ \\
\hline $56.74 \pm 1.13$ & & $4.81 \pm 0.56$ & $2.12 \pm 0.15$ & $2.43 \pm 0.19$ \\
\hline $45.43 \pm 0.59$ & $12.89 \pm 1.23$ & $4.82 \pm 1.16$ & $0.51 \pm 0.11$ & \\
\hline $40.45 \pm 0.83$ & $13.45 \pm 1.26$ & $6.73 \pm 1.03$ & & \\
\hline $36.37 \pm 1.06$ & $16.84 \pm 1.58$ & $7.31 \pm 0.94$ & & \\
\hline $29.48 \pm 0.60$ & $48.57 \pm 4.42$ & $10.62 \pm 1.45$ & & \\
\hline $24.72 \pm 0.81$ & $84.37 \pm 7.93$ & $12.98 \pm 1.85$ & & \\
\hline $19.13 \pm 1.13$ & $48.07 \pm 6.35$ & $25.74 \pm 3.58$ & & \\
\hline $17.09 \pm 1.18$ & $26.20 \pm 3.63$ & $43.97 \pm 6.29$ & & \\
\hline $16.81 \pm 1.25$ & $16.49 \pm 1.29$ & $62.58 \pm 4.99$ & & \\
\hline $14.72 \pm 1.37$ & $3.94 \pm 0.47$ & $93.30 \pm 11.09$ & & \\
\hline $13.25 \pm 1.51$ & & $184.64 \pm 14.00$ & & \\
\hline $9.64 \pm 1.99$ & & $193.38 \pm 16.97$ & & \\
\hline Energy $(\mathrm{MeV})$ & $\sigma$ Co-57 (mb) & $\sigma$ Co-58 (mb) & $\sigma$ Co-60 (mb) & $\sigma \mathrm{Mn}-54(\mathrm{mb})$ \\
\hline $70.08 \pm 0.54$ & $33.15 \pm 2.31$ & $39.50 \pm 2.84$ & $10.06 \pm 1.56$ & $3.89 \pm 0.41$ \\
\hline $69.99 \pm 0.55$ & $32.18 \pm 2.15$ & $39.92 \pm 2.94$ & & $3.58 \pm 0.56$ \\
\hline $69.73 \pm 0.59$ & $33.21 \pm 1.94$ & $39.40 \pm 2.42$ & $10.88 \pm 1.32$ & $3.92 \pm 0.36$ \\
\hline $63.86 \pm 0.86$ & $37.17 \pm 1.55$ & $31.05 \pm 1.41$ & $10.45 \pm 1.20$ & $4.53 \pm 0.34$ \\
\hline $63.49 \pm 0.92$ & $37.83 \pm 1.48$ & $30.79 \pm 1.34$ & $10.13 \pm 1.27$ & $4.82 \pm 0.38$ \\
\hline $57.55 \pm 1.07$ & $51.58 \pm 4.73$ & $30.74 \pm 3.00$ & $12.25 \pm 2.58$ & $4.37 \pm 0.67$ \\
\hline $57.12 \pm 1.09$ & $52.86 \pm 4.26$ & $30.47 \pm 2.52$ & $12.42 \pm 1.71$ & $4.53 \pm 0.50$ \\
\hline $56.74 \pm 1.13$ & $53.01 \pm 3.09$ & $30.95 \pm 1.91$ & $12.65 \pm 2.66$ & $4.17 \pm 0.38$ \\
\hline $45.43 \pm 0.59$ & $26.17 \pm 2.32$ & $52.34 \pm 4.88$ & $10.39 \pm 2.88$ & \\
\hline $40.45 \pm 0.83$ & $4.96 \pm 0.52$ & $61.63 \pm 5.72$ & $8.19 \pm 2.30$ & \\
\hline $36.37 \pm 1.06$ & $0.76 \pm 0.22$ & $50.22 \pm 5.35$ & $4.89 \pm 1.77$ & \\
\hline $29.48 \pm 0.60$ & & $7.90 \pm 0.76$ & & \\
\hline $24.72 \pm 0.81$ & & & & \\
\hline $19.13 \pm 1.13$ & & & & \\
\hline $17.09 \pm 1.18$ & & & & \\
\hline $16.81 \pm 1.25$ & & & & \\
\hline $14.72 \pm 1.37$ & & & & \\
\hline $13.25 \pm 1.51$ & & & & \\
\hline $9.64 \pm 1.99$ & & 47 & & \\
\hline
\end{tabular}


Table 7 (continued): experimental cross section values for Cu-nat(p,x)Zn-62,65, Ni-57, Co-56,57,58,60, Cu-61,64, Mn-54 reactions.

\begin{tabular}{ccc}
\hline Energy $(\mathrm{MeV})$ & $\sigma \mathrm{Cu}-61(\mathrm{mb})$ & $\sigma \mathrm{Cu}-64(\mathrm{mb})$ \\
\hline $70.08 \pm 0.54$ & $65.72 \pm 4.96$ & $44.02 \pm 7.03$ \\
$69.99 \pm 0.55$ & $68.72 \pm 5.20$ & $45.18 \pm 9.32$ \\
$69.73 \pm 0.59$ & $65.85 \pm 4.39$ & $42.16 \pm 9.42$ \\
$63.86 \pm 0.86$ & $68.75 \pm 3.63$ & $44.49 \pm 9.12$ \\
$63.49 \pm 0.92$ & $69.31 \pm 3.70$ & $38.54 \pm 8.71$ \\
$57.55 \pm 1.07$ & $81.59 \pm 8.08$ & $49.78 \pm 10.34$ \\
$57.12 \pm 1.09$ & $79.75 \pm 7.09$ & $54.57 \pm 11.50$ \\
$56.74 \pm 1.13$ & $80.73 \pm 5.32$ & $55.66 \pm 7.31$ \\
$45.43 \pm 0.59$ & $120.22 \pm 11.03$ & $60.05 \pm 12.96$ \\
$40.45 \pm 0.83$ & $169.43 \pm 15.31$ & $67.08 \pm 11.19$ \\
$36.37 \pm 1.06$ & $183.10 \pm 16.66$ & $71.25 \pm 12.13$ \\
$29.48 \pm 0.60$ & $106.57 \pm 10.81$ & $86.10 \pm 18.28$ \\
$24.72 \pm 0.81$ & $9.11 \pm 5.43$ & $112.26 \pm 26.08$ \\
$19.13 \pm 1.13$ & & $68.90 \pm 18.01$ \\
$17.09 \pm 1.18$ & & $40.96 \pm 14.06$ \\
$16.81 \pm 1.25$ & & $35.43 \pm 10.48$ \\
$14.72 \pm 1.37$ & & $12.63 \pm 2.82$ \\
$13.25 \pm 1.51$ & & \\
$9.64 \pm 1.99$ & & \\
\hline
\end{tabular}

